\title{
إدارة وقت الفراغ لدي الشباب الجامعي وعلاقته بالاستقرار الأسري
}

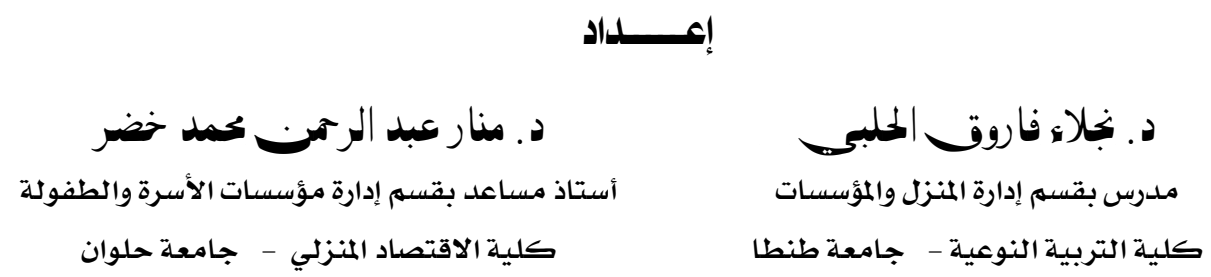

مجلة بحوث التربية النوعية - جامعة المنصورة

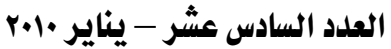




\section{إدارة وقت الفراغ لدي الشباب الجاهعي وعلاقته بالاستقرار الأسري}

$$
\text { إعـــداد }
$$

$$
\text { د. منار عبد الرحمزمحمد خضر }
$$

\section{هاخ مص الدراسة}

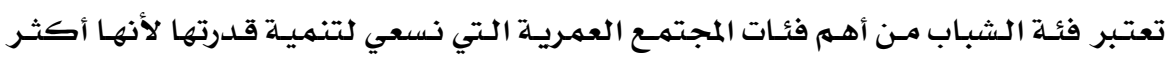

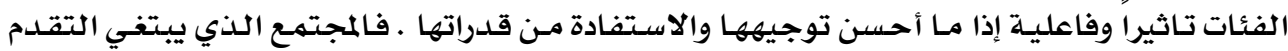

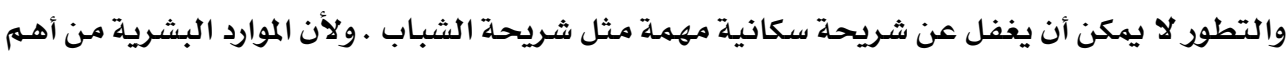

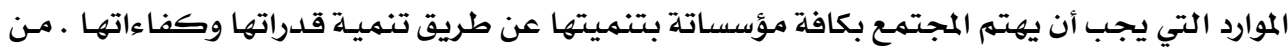

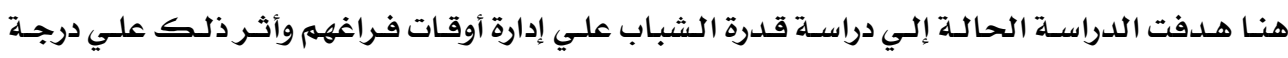

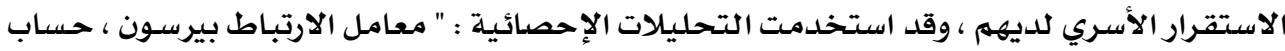

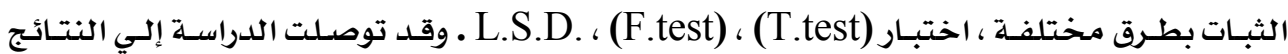
التتادية :

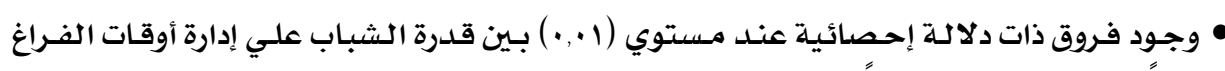

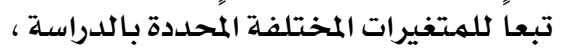

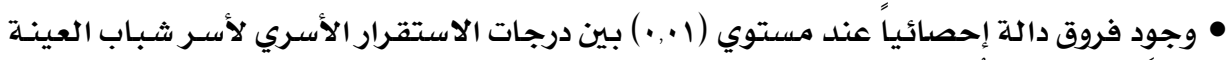
تبعا للمتغيرات المحلددة بالدراسلة .

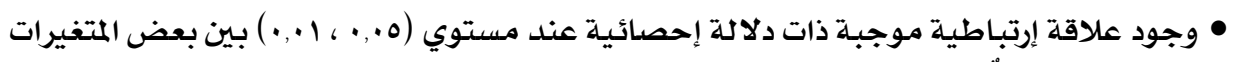

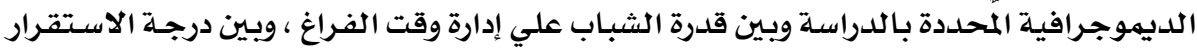

$$
\text { الأسـري لدي أسر شبـاب العينة . }
$$

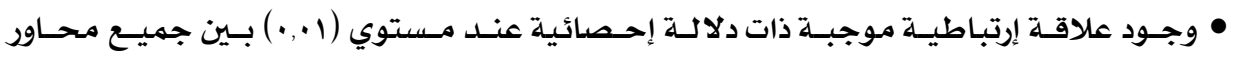

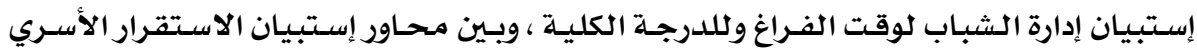

$$
\text { وللدرجـة الكلية . }
$$

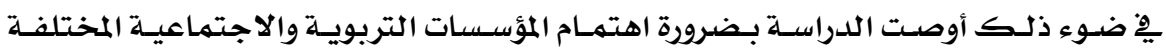

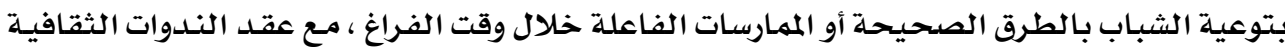

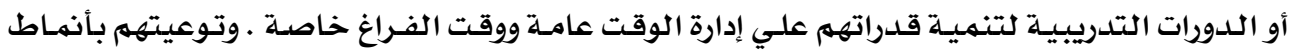

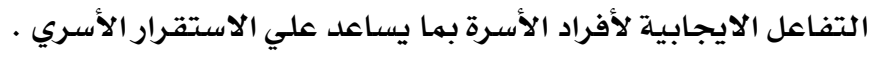


Summary

\section{Managing The Leisure Jime Among The University Youth And Jts Relation With Family Stability}

\section{Dr. Naglaa Farouk El Halaby}

Lecturer in the home management and institutions Dept.

Specific Education faculty - Tanta University
Dr. Manar Abd El Rahman Khader

Ass. Prof at management of family and childhood institutions Dept. Home Economics faculty - Helwan University

Youth group is considered as one of the most important age categories in the society which is endeavoring to develop its capabilities because it is the most effective category and the most effective activity in case it has been directed in the better way and to be benefited from its capacities. The society which aims at development and advance, cannot ignore a residential group as to its importance such as the your one. At the same time because the human resources is considered as one of the most important resources for which the society must give its concern in all its institutions to develop it by means of the development of its capabilities and its capacities . Hence, this study has aimed at the study of the abilities of the youth on the management of their leisure times and the effect of this on the family stability degree at them, the statistic analyses have been used : " coefficient of correlation ( Person), the account of the stability in its various methods, F. Test, L.S.D. , T. test .

\section{The study has reached the following results :}

- There are significant statistical differences at the level (0.01) between the capacity of the youth on managing the times of the leisure according to the different changes in the study .

- There are significant statistical differences at the level (0.01) between the degrees of the family stability for the matter of the youth, the sample is according to the specific changes .

- There are significant correlation and positive $\quad(0.01 .0 .05)$ between some of the changes in demography specified into the study and between the abilities of the youth on managing the leisure time, and between the degree of the family stability at the sample of the youth families . 


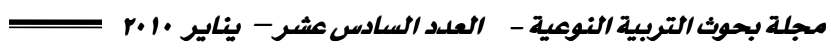

The study has recommended that : necessity of concern from the educational foundations and the various social ones for the awareness of the youth according to the sound and correct methods or the effective practices during the leisure time. In addition to holding the cultural seminars or the training courses for the development of their capacities on managing the time in general and the leisure time in particular, and the awareness of the your with the kinds of the positive effectiveness for the individuals of the family, the matter which shall help on the family stability . 


\section{إدارة وقت الفراغ لدي الشباب الجاهعي وعلاقته بالاستقرار الأسري}

$$
\text { إعـــداد }
$$

$$
\text { د. منار عبد الرحمتممد خضر }
$$

\section{مقدهمة البحث مقاث}

التنمية عملية شاملة تضرب جذورها ِِّ مختلف جوانب الحياة وتنتقل بالمجتمع إلي مرحلة

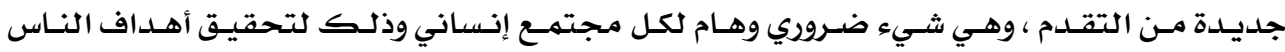

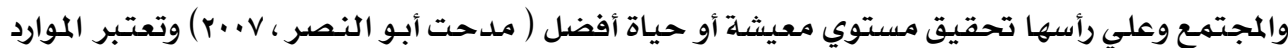

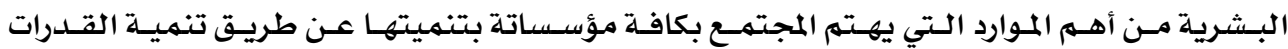

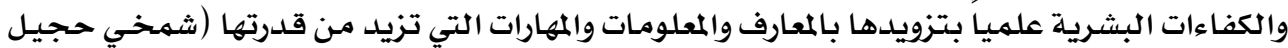
. (r...r.

الأسرة هي الوحدة البنائية الأساسية ِِّْ بناء المجتمعات الأنسانية ، فهي التي تقوم بالدور

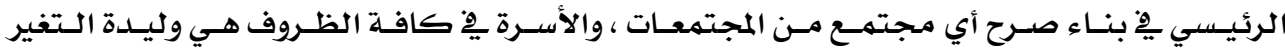

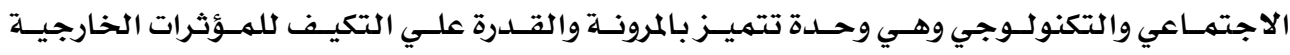

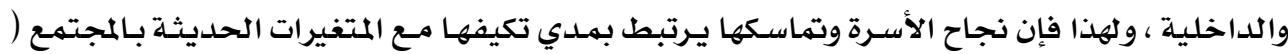

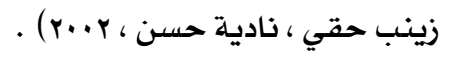

وتعتبر فئدة الشباب مـن أهم فئـات المجتمـع العمرية التي يسعي لتنميـة قدرتها لأنها أكثر

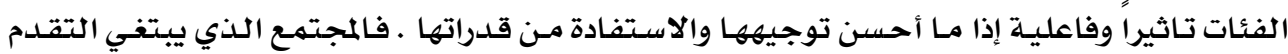

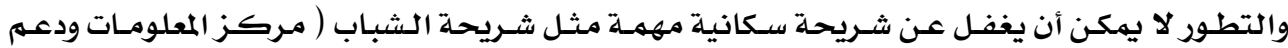

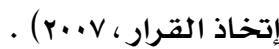

إن الوقت من أهم العوامل المؤثرة على حيـاة الفرد، إذ إنه يشترك مـع جميـع مـوارده البشرية

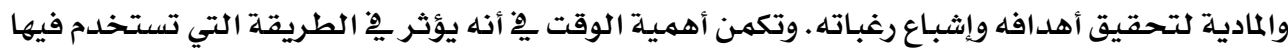

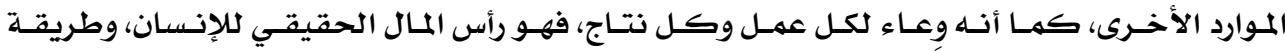

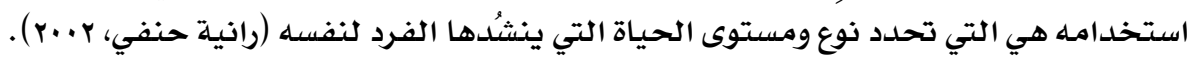

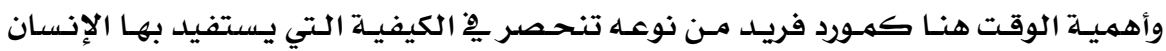

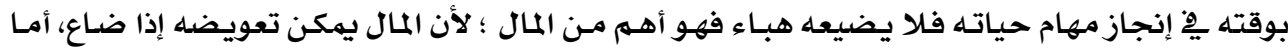
الساعة التي تنقضي من عمر الإنسان فلا يمكن استرجاعها أو تعويضها (أيمن مزاهرة وآخرون، ب .. r).

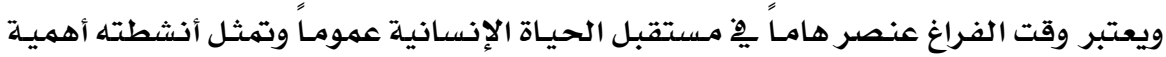

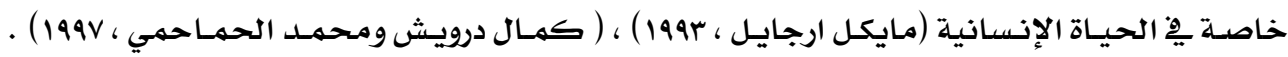

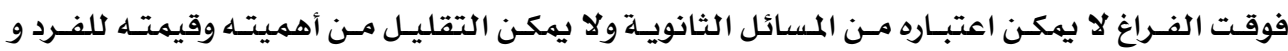




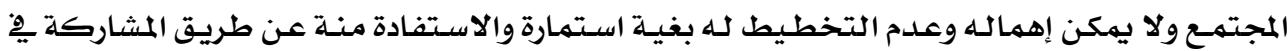

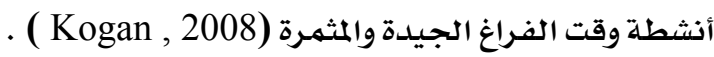

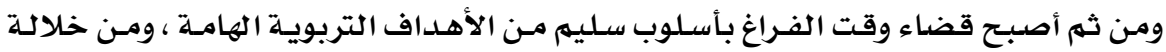

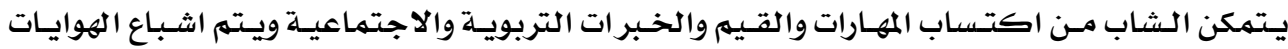

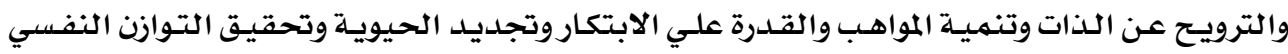

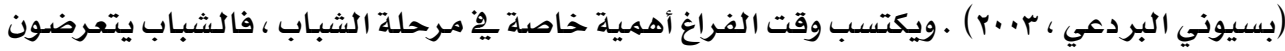

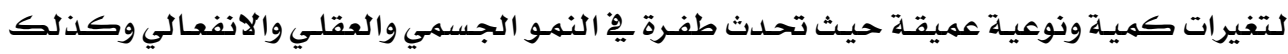

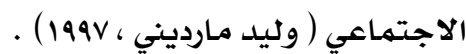

ولكن وقت الفراغ سلاح ذو حدين فهو إما أن يرتقي بشخصية الانسـان وفكرة وروحـة ووجدانـة

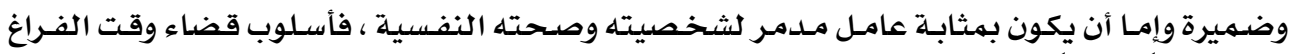

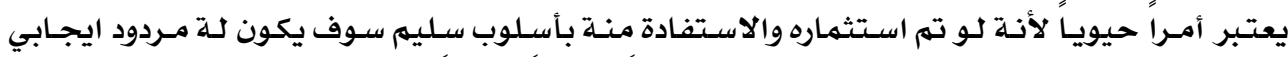

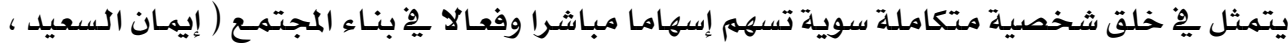

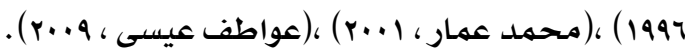

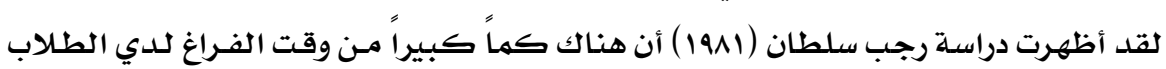

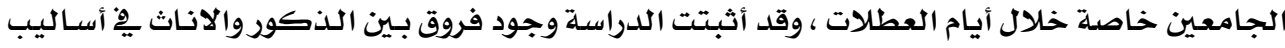

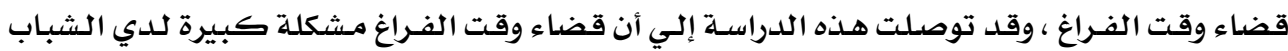

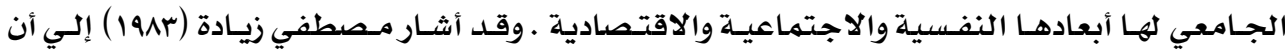
القصور مِّ الاستفادة من وقت الفراغ لدي الشباب يؤثر علي معدلات التحصيل للطلاب .

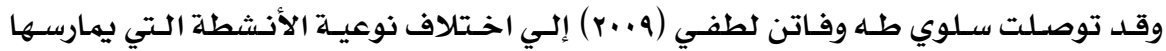

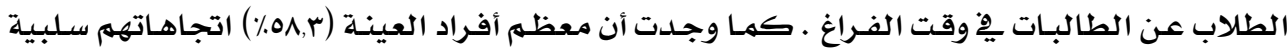

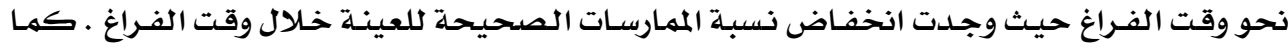

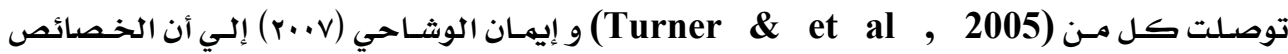

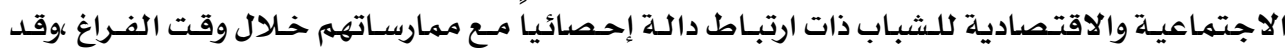

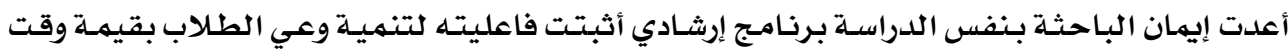
الفراغ

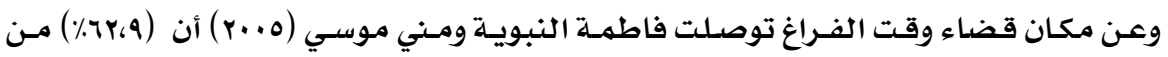

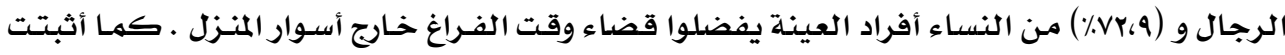

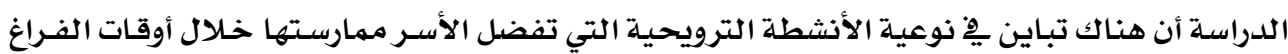

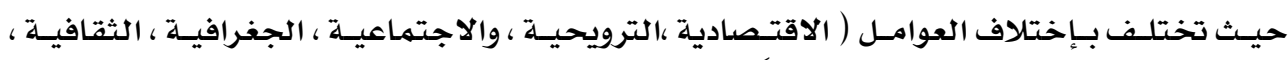

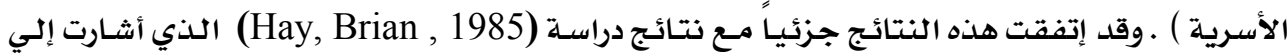

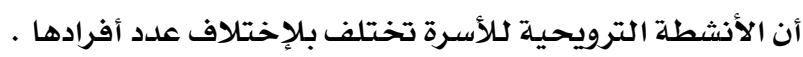




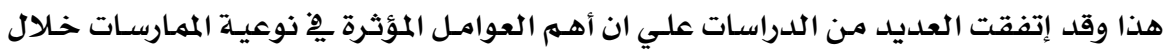

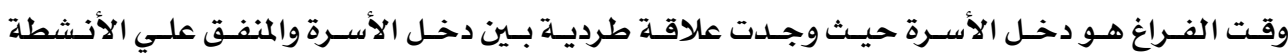

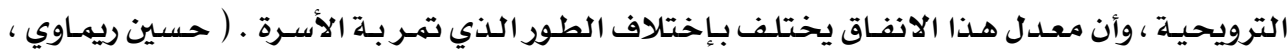

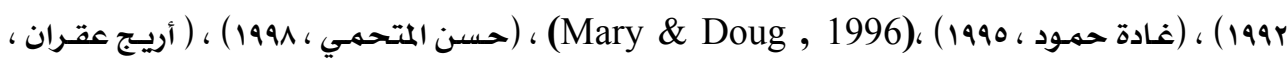

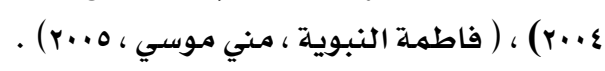

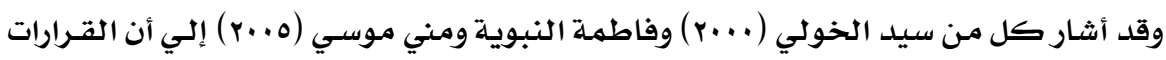

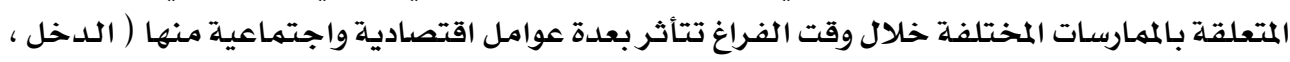

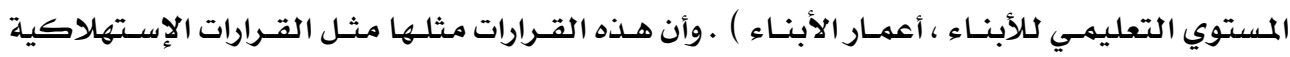

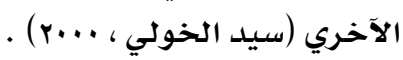

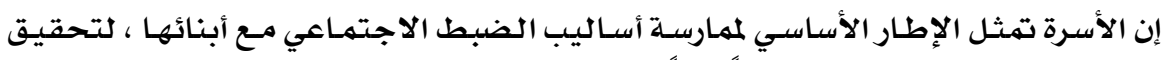

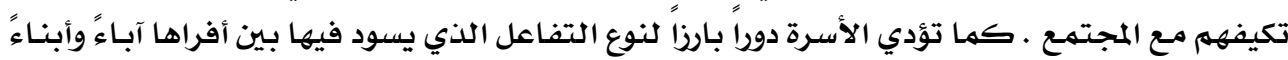

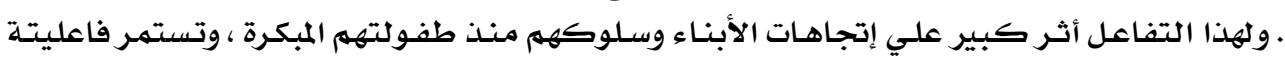

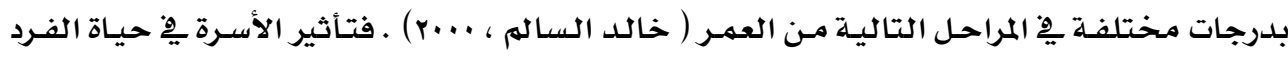

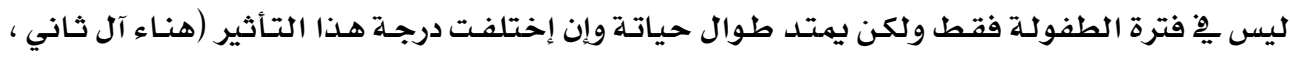

كما أن طبيعة العلاقات الأسرية لها تأثير كبير علي حياة الشباب ومستقبلهم ، فقد أشار

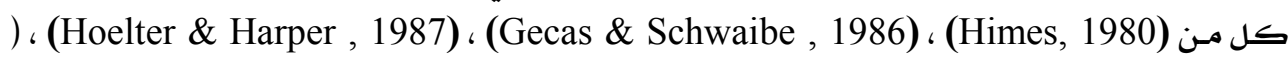

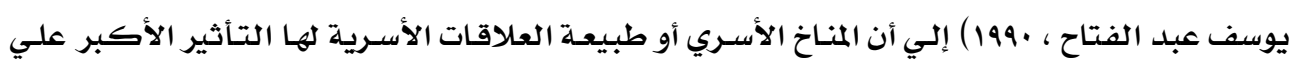

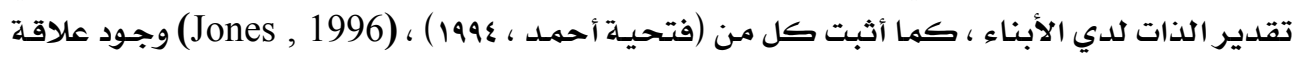

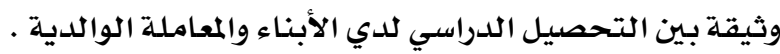

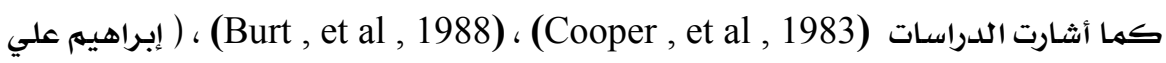

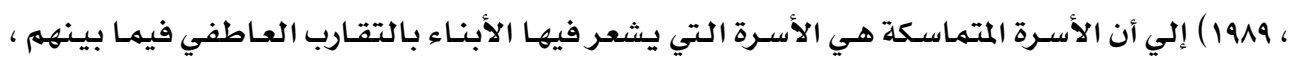

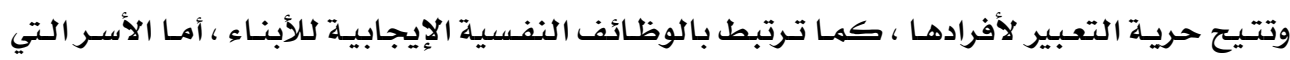

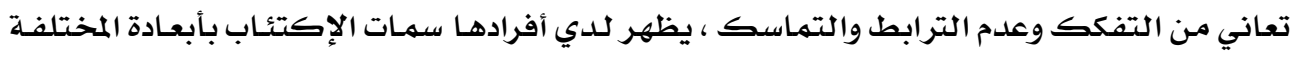

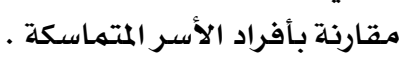

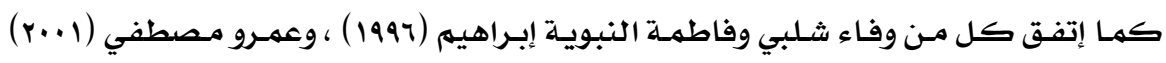

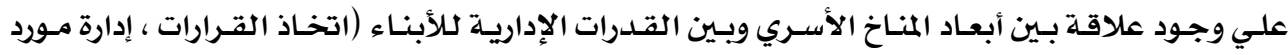

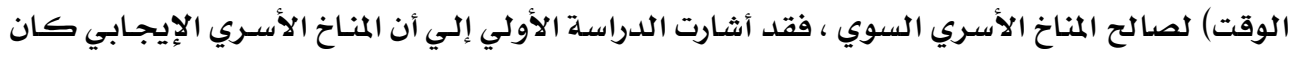

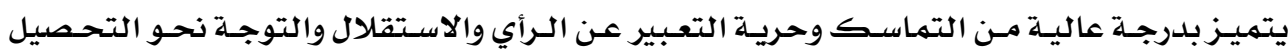

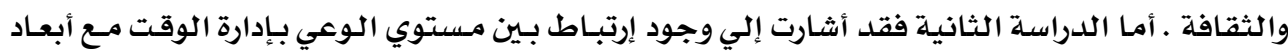

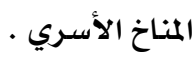




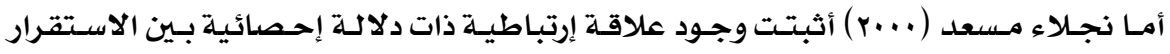

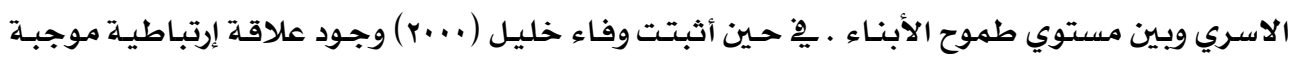

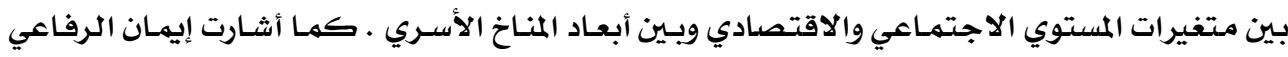

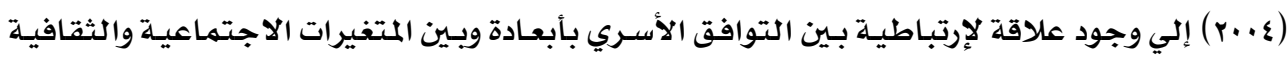
والاقتصادية لأسر العينـة .

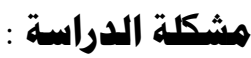

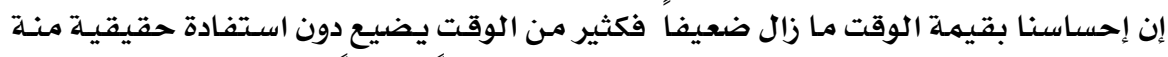

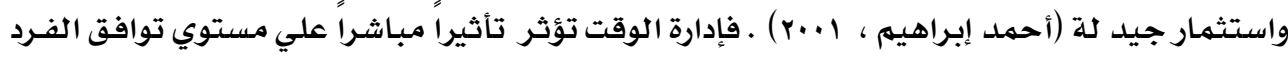

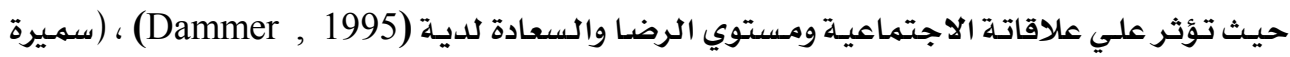

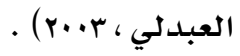

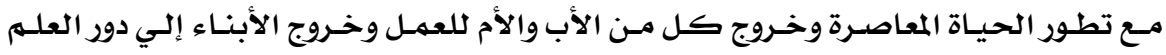

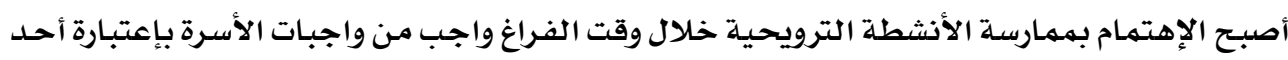

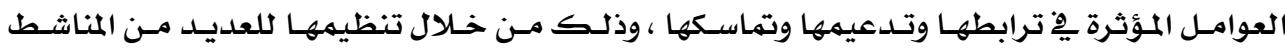

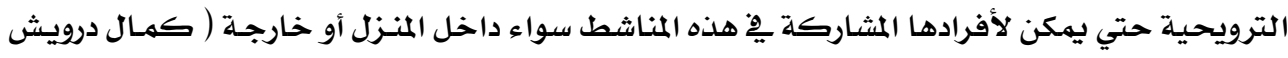

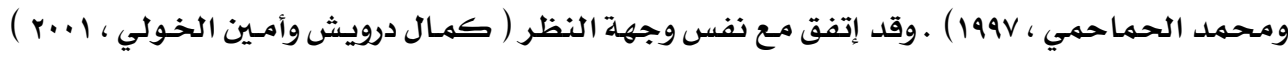

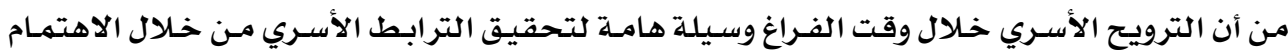
بالوظيفة الاجتماعية والثقافية لكلأسرة .

وقد أشـار (Bajan , 1998) إلى أن التكنولوجيا والتقنيـات الحديثة مثل : الحاسب الآلىي

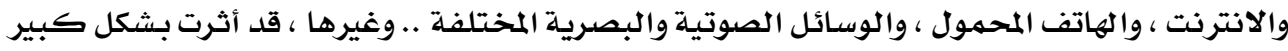

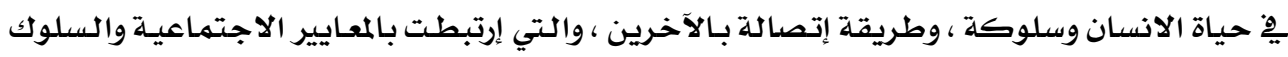

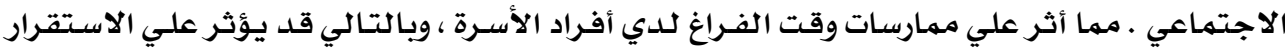
الأسـري الأن

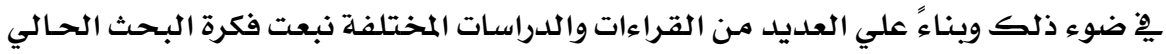

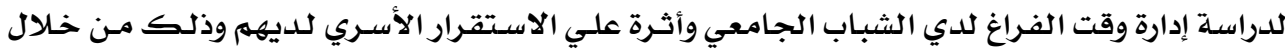
الإيجابـة علي التسـاؤلات التتاليـة :

ما أثر المتغيرات الديهوجرافية لعينة الدراسـة (النوع ، تعليه الأب والأم ، مهنة الأب ، عمل الأم ،

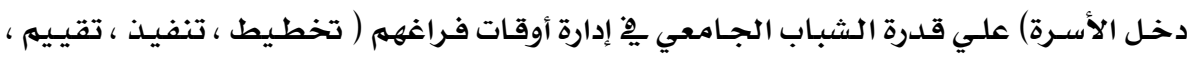

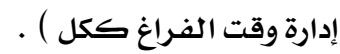
ما أثر المتغيرات الديموجرافية لعينة الدراسـة (النوع ، تعليم الأب والأم ، مهنـة الأب ، عمل الأم ،

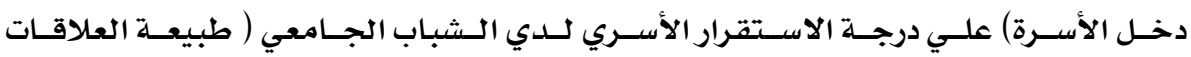
الاجتماعية للأسرة ، نمط التفاعل بين أفراد الأسرة ، الاستقرار الأسري كري ككل ). 
مـا مـدي العلاقة بـين المتغيرات الديهوجرافية للشباب الجـامعي وبين قدرتهمه علدي إدارة أوقات

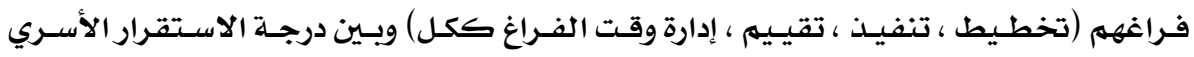

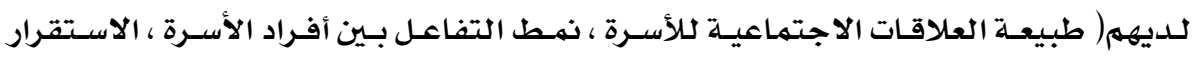

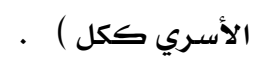

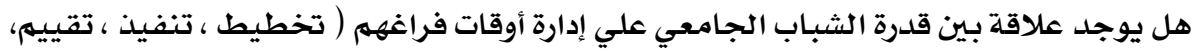

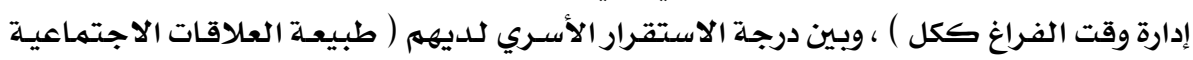

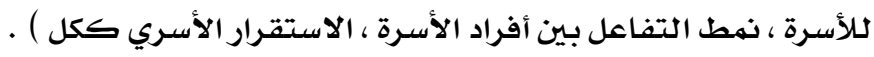

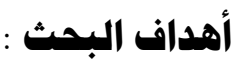

$$
\text { يهدف البحث الحالي إلي : }
$$

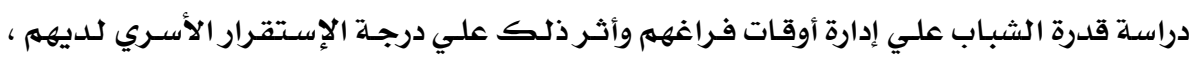

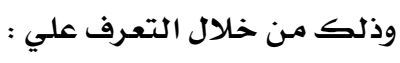

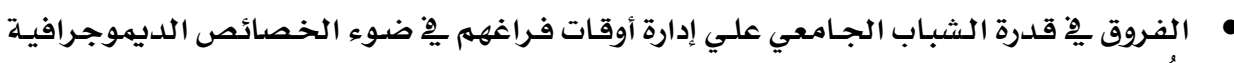
المحددة للعينة.

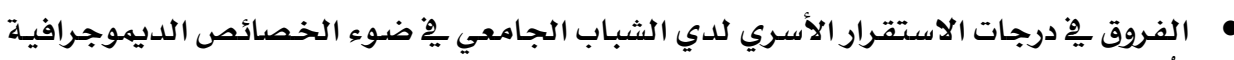

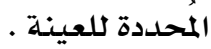
•العلاقة بـين المتغيرات الديهوجرافيـة للشباب الجـامعي وبـين قدرتهم علـي إدارة أوقات فراغهم

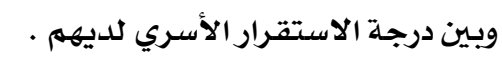

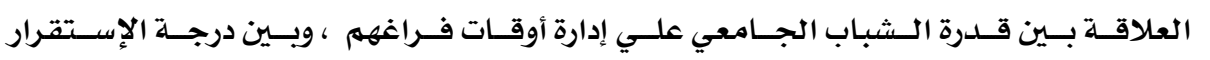

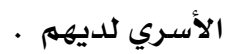

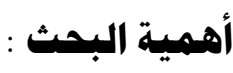

تظهر أهمية البحث من خلال : إلقاء الضوء علي شريحة سكانية هامة من شرائح المجتمع وهي فئة الشباب حيث يتوافر لديها

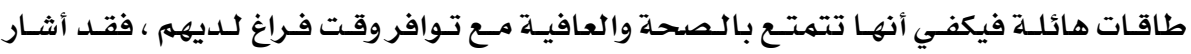

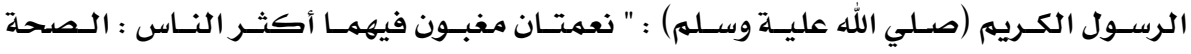

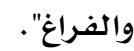

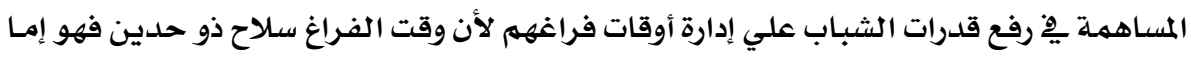

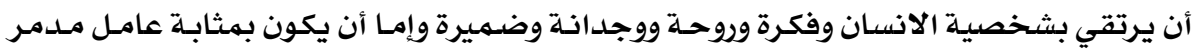
لشخصيتة وصحتة النفسية .

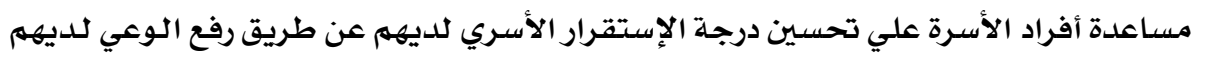

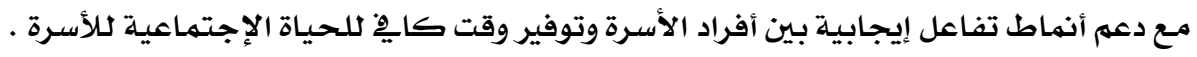

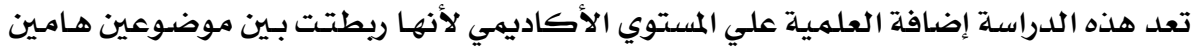

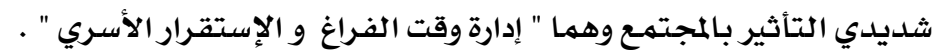




\section{الأسلوب البحثي

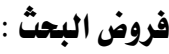

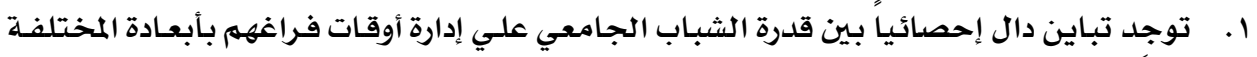

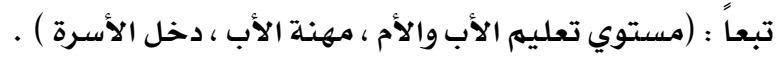

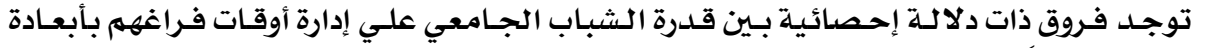

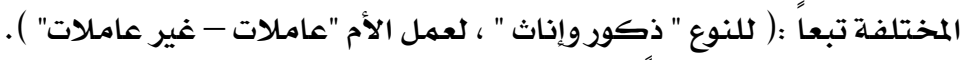

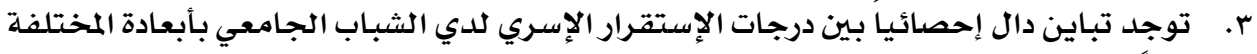

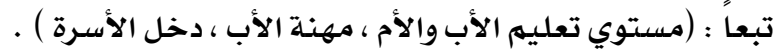

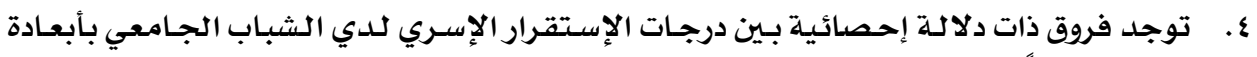

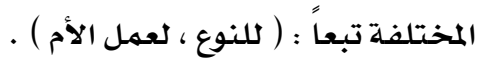

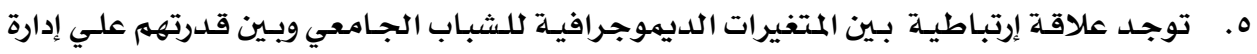

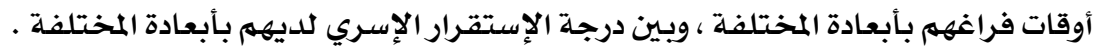

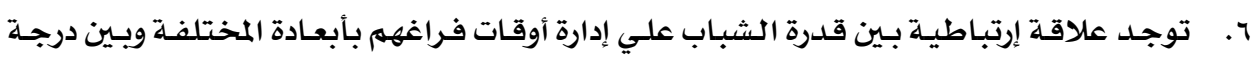

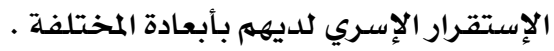

منهج البحث :

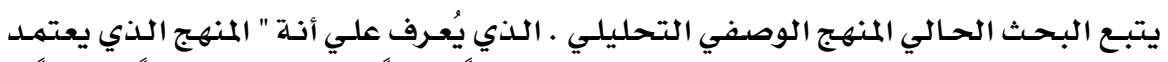

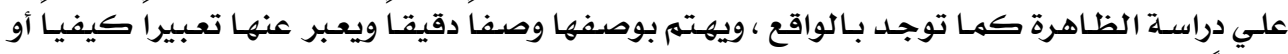

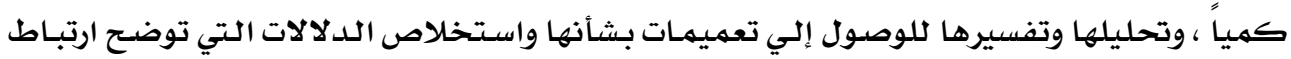

متغير بمتغير آخر " (ذوقان عبيدات وآخرون ، ج... ب) .

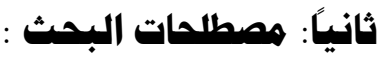

Time Management إدارة الوقت

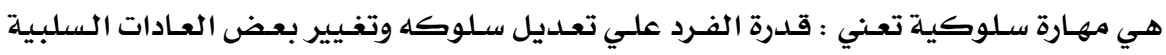

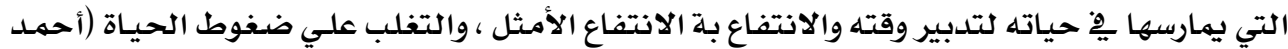

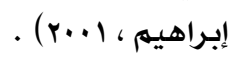

Leisure Time

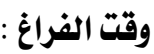

يعرف وقت الفراغ علي أنة " الوقت المتبقي بعد إنقضاء الوقت المخصص للأنشطة الضرورية

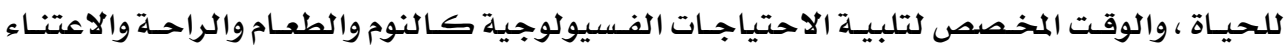

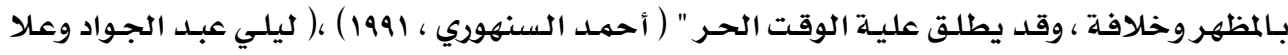

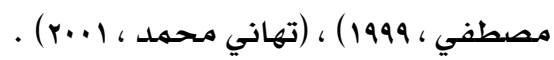


البـاحثتين إدارة وقت الفـراغ إجـرائيـاً علسي أنـة " قـدرة الشبـاب علـي تـدبير أوقات فراغهم عن

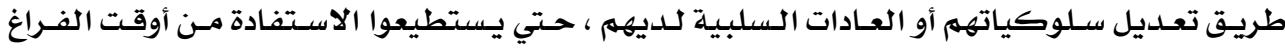

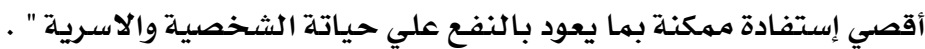
Family Stability الاستقرار الأسري:

هو العلاقة الأسريـة الناجحة التي تقوم علي التفاعل الدائم بين أفراد الأسـرة جميعـاً ، والتي

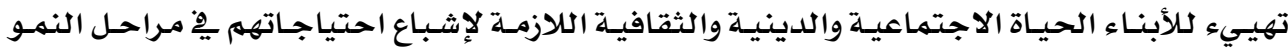
المختلفة ، وتتسهم هذه العلاقة بسيادة المحبـة والديهقراطية والتعاون بـين أفراد الأسـرة يف إدارة شـئونهم

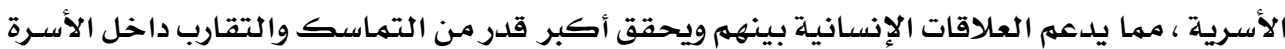

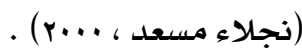

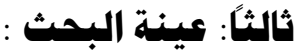

تكونت عينـة البحـث مـن (YVO) شـاب جـامعي مـن البــين والبنـات ومسن مستويـات إجتهماعيـة

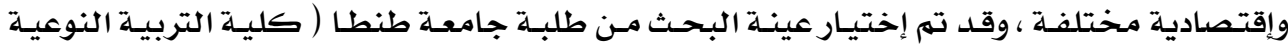

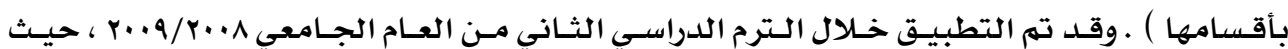
إستغرق التطبيق شهري ( مارس وإبريل) .

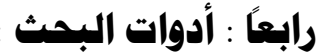

(إعداد الباحثتين) 1. استمارة بيانات عامة .

r. استبيان " إدارة الشباب لوقت الفراغ " إعداد الباحثتين)

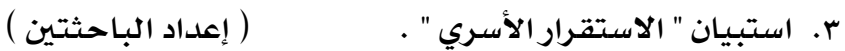

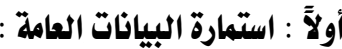

تم إعداد استمارة البيانات العـامـة للأسـرة بهدف الحصول علـي المعلومـات الكلازمـة عن الأسـرة ككل والشبـاب مفردات عينة الدراسـة ، حتى يـتم تحديــ الخصائص الديموجرافيـة للأسـر وللشبـاب ،

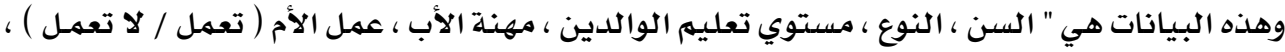

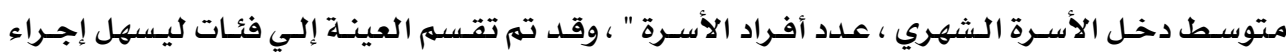

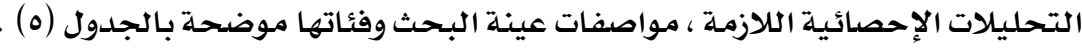

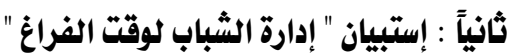

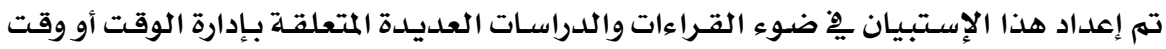

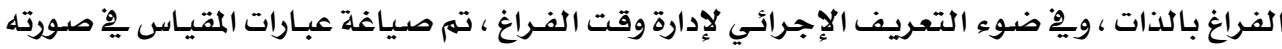

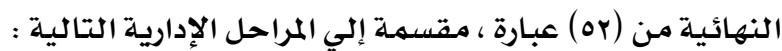

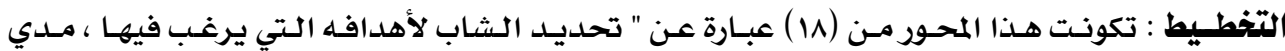

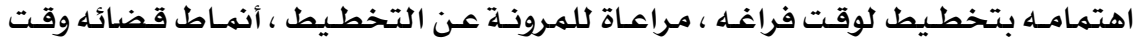

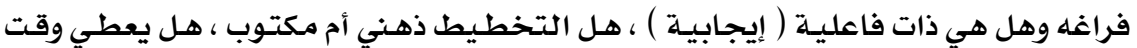


$\underline{\underline{2}}$ مجلة بحوث التربية النوعية - العلد السادس عشر- يناير •l.1 م

كايِّ لتخطيط وقت فراغه ، هل هناك وقت كايِّ مخصص للأنشطة الأسـرية ، مـا نهط

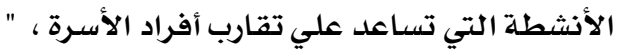

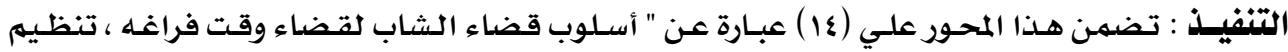

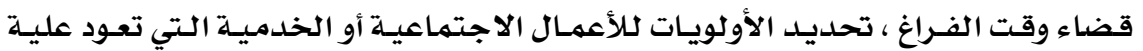

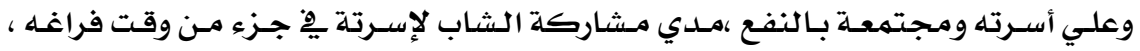

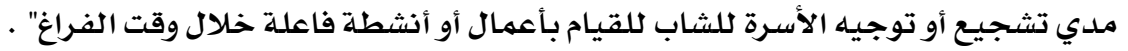
التقييه : تكون هذا المحور من (•r) عبارة عن " مـدي حرص الشباب علسي الالتزام بخططهم نحو وقت فراغهم ، وطموحاتهم نحو الاستفادة مستقبلاً من وقت الفراغ ، هل قام الشاب بتأجيل أو إلغـاء بعض الأعمال ، هـل فشل يْ تحقيق بعض الأهـداف أو الخطط ، تقيهـة الشخصي

$$
\text { نحو أسـاليب قضائه وقت فراغه ". }
$$

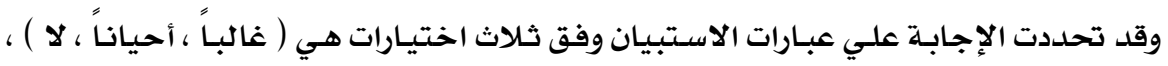

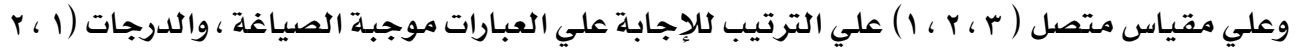

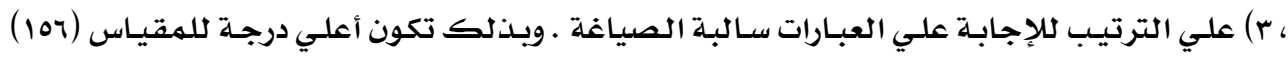

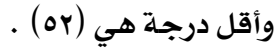
صدق الاستبيان : تم قياس صدق الاستبيان باستخدام الاتساق الداخلي وذلك بحسـاب معامل الارتبـاط

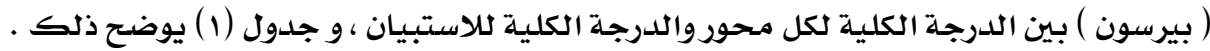

\begin{tabular}{|c|c|c|}
\hline الدلالة & الارتباط & المحاور \\
\hline$\cdot, \cdot 1$ & $\cdot, \wedge \varepsilon \vee$ & التخطيط \\
\hline$\cdot, \cdot 1$ & - arr & التنفيذ \\
\hline$\cdot, \cdot 1$ & $\cdot$, V07 & التقييم \\
\hline
\end{tabular}
جلدول (1) : قيم معاملات الإرتباط بين الدرجة الكلية لكل محوروالدرجة الكلية للإستبيان

يتضح من هـذا الجـدول أن معـاملات الارتبـاط كلهها دالـة عند مستتوي (1... ) لاقترابها مـن الواحد الصحيح مما يدل علي صدق وتجانس محاور الاستبيان .

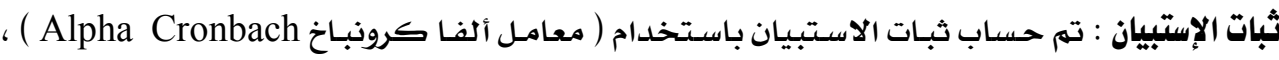

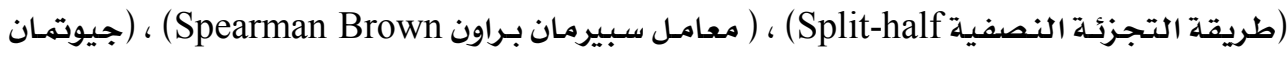

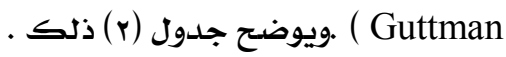


جدول (r) : قيم معاملات ثبات إستبيان " إدارة الشباب لوقت الفراغ " ومحاورة المختلفة

\begin{tabular}{|c|c|c|c|c|}
\hline جيوتمان & سبيرمان براون & التجزئَة النصفية & معامل ألفا & المحاور \\
\hline$\cdot, \mathrm{V} \wedge \varepsilon$ & $\cdot, 10$. & $\cdot, \mathrm{Vrq}$ & •, $\vee 99$ & التخطيط \\
\hline$\cdot, q \cdot V$ & . 94. & $\cdot, 179$ &., 917 & التتفيذ \\
\hline$\cdot, \wedge 1$ & $\cdot, 170$ & ש r, va & س & التقييم \\
\hline$\cdot, \wedge \vee 0$ & $\cdot 9 \cdot 9$ & س אוג, • & $\cdot, \Lambda \wedge \vee$ & الإستبيان ككل \\
\hline
\end{tabular}

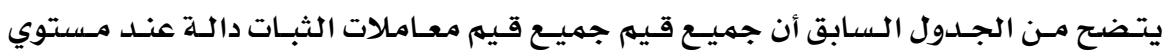

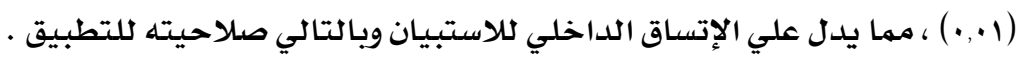

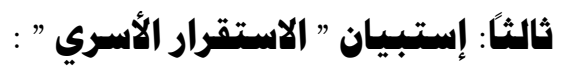

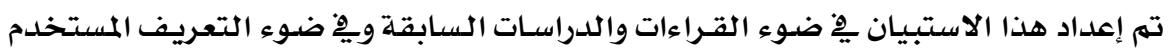

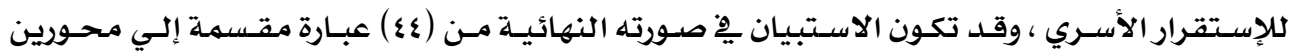
رئيسيين هما :

طبيعـة الحيـاة الاجتماعيـة داخـل الأسـرة : تضضمن هـذا المحـور (IV ) عبـارة عـن " العلاقـات

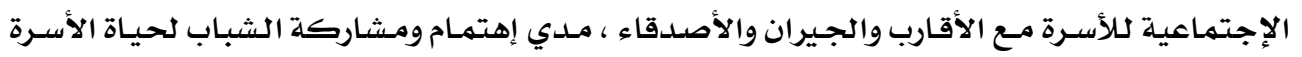

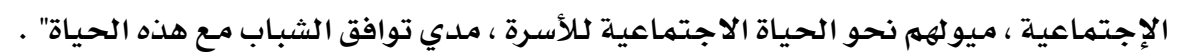

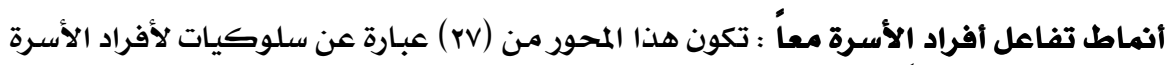

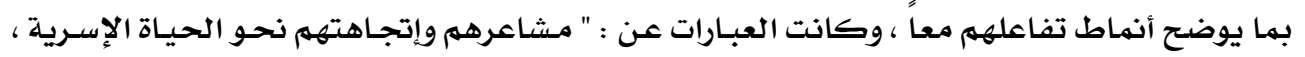

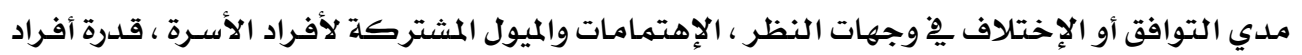

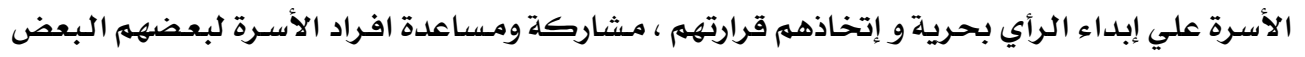

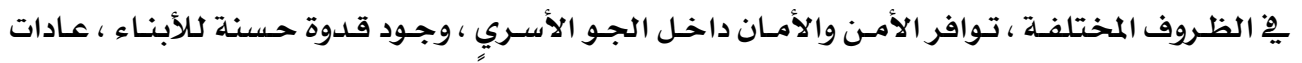

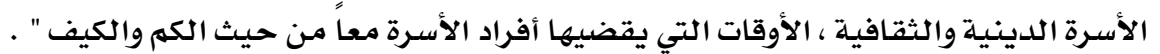

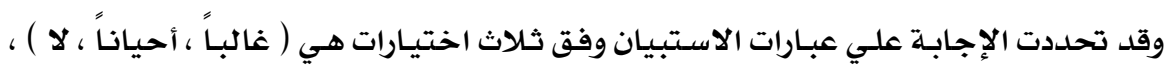

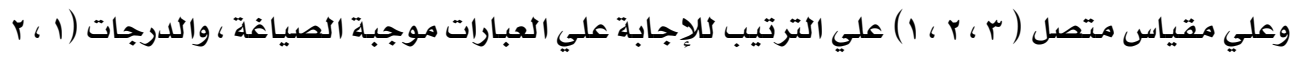

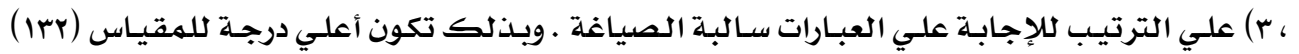

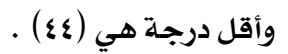

صدق الاستبيان : تم قياس صدق الاستبيان باستخدام الاتساق الداخلي وذلك بحسـاب معامل الإرتبـاط

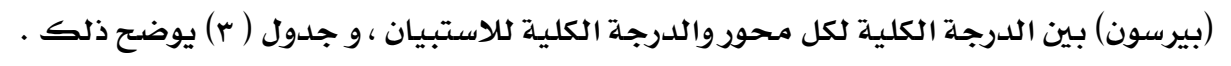




\begin{tabular}{|c|c|c|}
\hline الدلادلة & الارتباط & المحاور \\
\hline$\cdot, \cdot 1$ & $\cdot, \wedge \vee \mu$ & طبيعة الحياة الاجتماعية للأسرة \\
\hline$\cdot, \cdot 1$ & $\cdot 941$ & أنماط تفاعل أفراد الأسـرة معاً \\
\hline
\end{tabular}

يتضـح من هـذا الجـدول أن معـاملات الارتبـاط كلهها دالـة عنــ مستوي (1.,. ) لاقترابها مـن

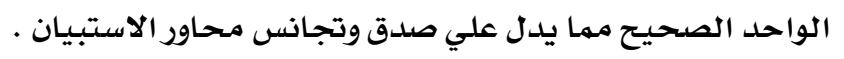

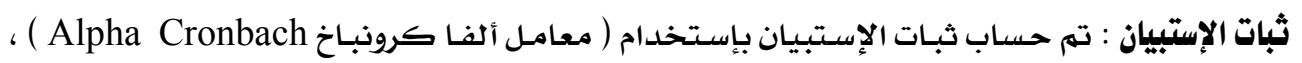

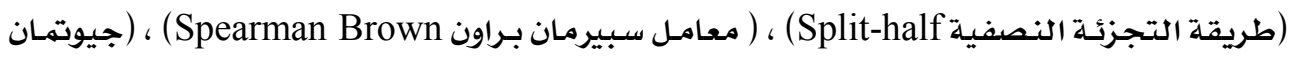

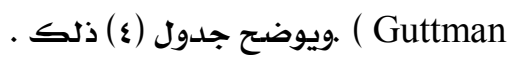
جدول ( ع) : قيهم معاملات ثبات إستبيان " الإستقرار الإسري " ومحاورة المختلفة

\begin{tabular}{|c|c|c|c|c|}
\hline جيوتمان & سبيرمان براون & التجزئة النصفية & معـامل ألفا & المحاور \\
\hline$\cdot$ •, & $\cdot, \Lambda \Lambda 1$ & $\cdot, \mathrm{VAM}$ & $\cdot, \wedge \varepsilon \wedge$ & طبيعة الحياة الإجتماعية للأسرة \\
\hline$\cdot, \wedge \wedge \varepsilon$ & $\cdot, 91 \varepsilon$ & $\cdot, \wedge \leqslant Y$ & $\cdot$ •, १৭६ & أنهاط تفاعل أفراد الأسـرة \\
\hline$\cdot$, AOr & $\cdot$ •, А९Y & $\cdot, \wedge \cdot 7$ & 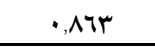 & الإستبيان ككل \\
\hline
\end{tabular}

يتضح من الجدول السابق أن جميع قيه جميع قيم معاملات الثبات دالة عند مستوي ( +., ) ،

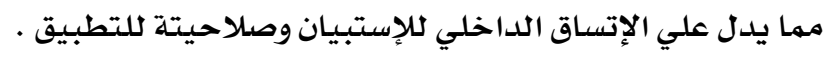

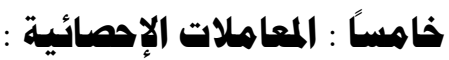

تم إجراء المعالجة الإحصائية للنتائج باستخدام برنـامـ (SpSS) وذلك لإجـراء التحلسيلات

$$
\text { والمعاملات الإحصائية الآتية : }
$$

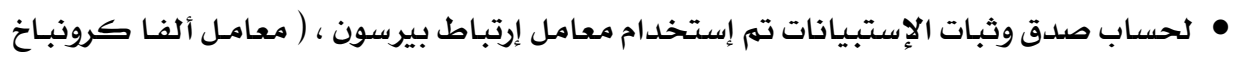

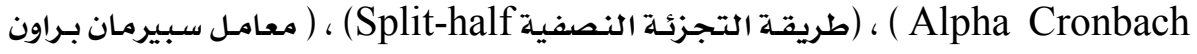

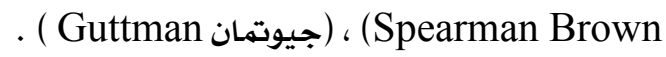

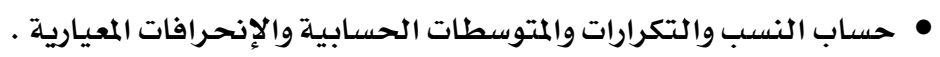

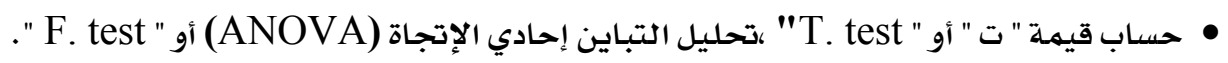

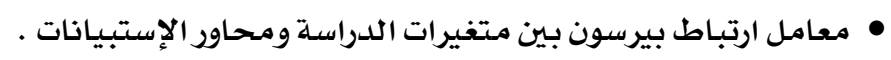

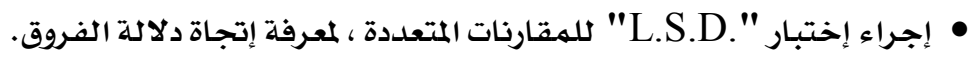


نتائج البحث (تصليلها وتفسيرها ومناقشتهها)

أولاً : النتائج الوصفية :

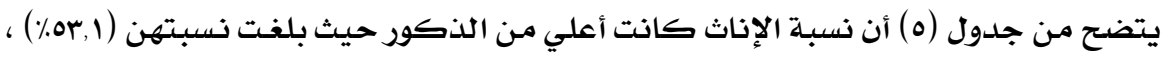

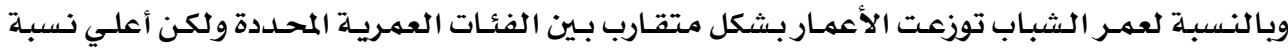

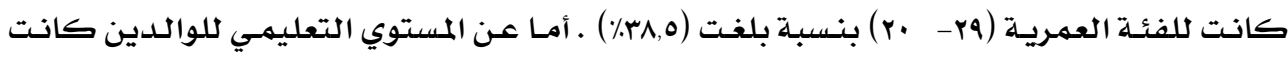

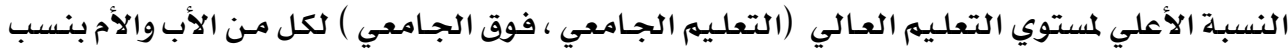

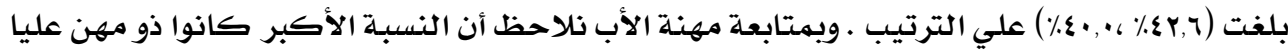

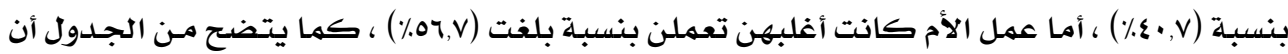

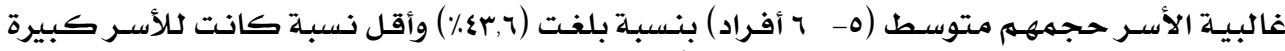

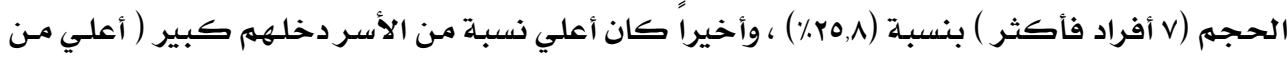
(و....

\begin{tabular}{|c|c|c|c|c|c|c|c|c|c|}
\hline النسبة ٪ & التكرار & الفئات & المتفيرات & م & النسبة \% & | التكرار & الفئات & المتفيرات & p \\
\hline $\begin{array}{l}r V, r \\
r r, \cdot \\
\varepsilon \cdot, r\end{array}$ & $\begin{array}{l}\text { vo } \\
\text { As } \\
\text { IIr }\end{array}$ & متوسطة & مهنة الأب & 0 & $\begin{array}{l}\varepsilon 7,9 \\
\text { or, }\end{array}$ & $\begin{array}{l}189 \\
1 \leqslant 9\end{array}$ & أنثي & النوع & 1 \\
\hline $\begin{array}{l}\Delta \eta, Y \\
\varepsilon r, r\end{array}$ & $\begin{array}{l}107 \\
119\end{array}$ & لا تعمل & عمل الأم & 7 & $\begin{array}{l}r \mu, 1 \\
r \Lambda, 0 \\
r \Lambda, \varepsilon\end{array}$ & $\begin{array}{l}91 \\
1.9 \\
81\end{array}$ & 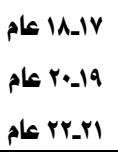 & عمر الشاب & $r$ \\
\hline $\begin{array}{l}r \cdot, \uparrow \\
\{r, \uparrow \\
r 0, \Lambda\end{array}$ & $\begin{array}{l}\Delta \varepsilon \\
i r \\
r\end{array}$ & متوسط & حجم الأسرة & $v$ & $\begin{array}{l}r \xi, Y \\
r Y, Y \\
\xi r, Y\end{array}$ & $\begin{array}{l}91 \\
9 . \\
118\end{array}$ & منخفض مالي & مستوي تعليم الأب & $r$ \\
\hline $\begin{array}{l}r q, \xi \\
r 1, r \\
r q, r\end{array}$ & $\begin{array}{l}11 \\
19 \\
1 \cdot 1\end{array}$ & مترفظف مرتفع & دخل الأسرة & $\wedge$ & $\begin{array}{l}r \Lambda, Y \\
r 1, r \\
\varepsilon, .,\end{array}$ & $\begin{array}{l}\text { va } \\
19 \\
11 .\end{array}$ & متخفض مالي & مستوي تعليه الأم & $\xi$ \\
\hline 1.. & rro & & المجموع & & 1.. & rro & & المجموع & \\
\hline
\end{tabular}

ثانياً : النتائج في ضوى فروض البحث :

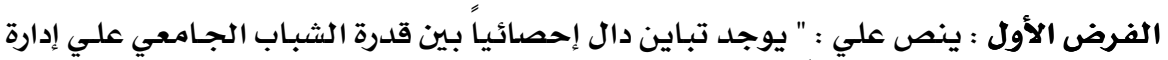

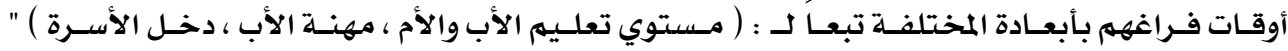

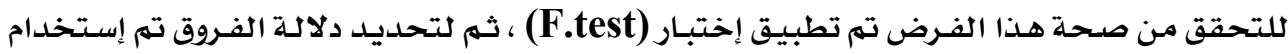




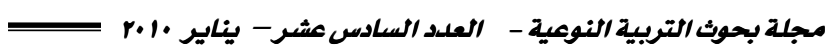

إختبـار أقل فـرق معنـوي (L.S.D. ) للتعـرف علـي إتجـاة دلالــة الفـروق ـوالجـداول مـن (ج) إلـي (rا) توضع ذلك

جدول (7) يوضح وجود تفاعل دال إحصائياً بـين قدرة الشبـاب علي إدارة أوقـات فراغههم تبعـاً

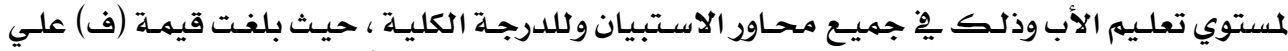

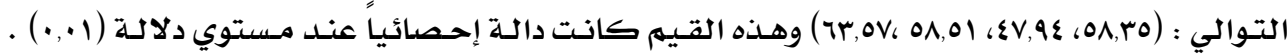

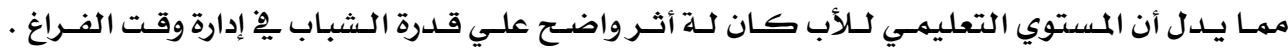

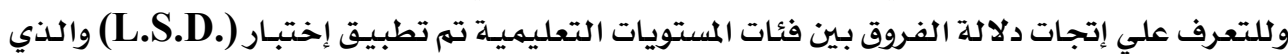

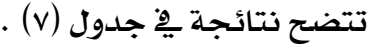
جدول (؟) : تحليل التباين بين قدرة الشباب الجامعي علي إدارة أوقات فراغهم تبعاً لمستوي تعليه الأب ( باستخدام F.test ) حيث ن الكلية

\begin{tabular}{|c|c|c|c|c|c|c|}
\hline مستوى & 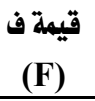 & متوسط & دارجات & المجربعات & مصلدر التباين & المحاور \\
\hline دالة & $\Delta \Lambda$, ro & $\begin{array}{l}\text { orrr,q1 } \\
91,97\end{array}$ & $\begin{array}{l}r \\
r Y r \\
r Y \varepsilon\end{array}$ & 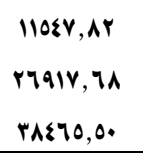 & 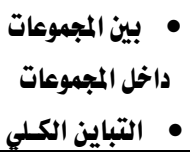 & اــ التخطيط \\
\hline دالة & $\xi \curlyvee, १ \xi$ & $\begin{array}{l}\text { orrr,or } \\
119,8 \text {. }\end{array}$ & $\begin{array}{l}r \\
r r r \\
r Y \varepsilon\end{array}$ & 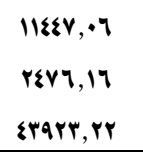 & 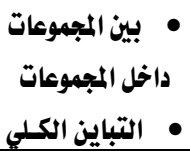 & ــ التنفيذ: \\
\hline دالة & 01,01 & $\begin{array}{l}\text { I. } \$ 0 \Lambda, Y O \\
\text { IVA,VY }\end{array}$ & $\begin{array}{l}r \\
r Y r \\
r Y \varepsilon\end{array}$ & $\begin{array}{l}\text { r.917, ri } \\
\text { \$19110,7r } \\
\text { 790rr, r\& }\end{array}$ & 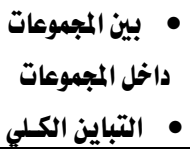 & بــ التقييم \\
\hline دالة & Tr,or & $\begin{array}{l}\text { DoTrr, Yq } \\
\text { AV\&,qr }\end{array}$ & $\begin{array}{l}r \\
r Y r \\
r Y \varepsilon\end{array}$ & $\begin{array}{l}\text { IIIr\&O, Oq } \\
\text { rrYqA1,•A } \\
\text { r\&qrYq, Tr }\end{array}$ & 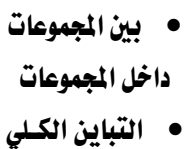 & كـ إدارة وقـت الفراغ ككل : \\
\hline
\end{tabular}

جدول ( v ) اختبار LSD للمقارنات المتعددة

\begin{tabular}{|c|c|c|c|}
\hline 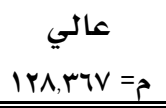 & مت متوسط & 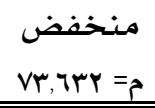 & تعليم الأب \\
\hline & & - & منخفض \\
\hline & - & $* * r r, V r \varepsilon$ & متتوسط \\
\hline - & $\nLeftarrow$ \& , , . & 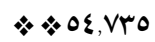 & عالى \\
\hline
\end{tabular}




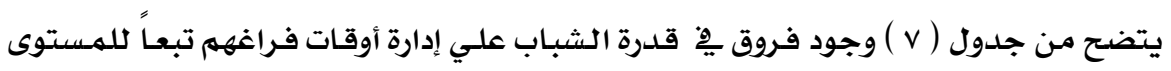

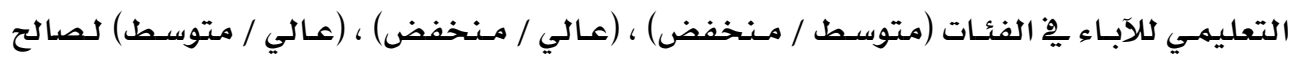

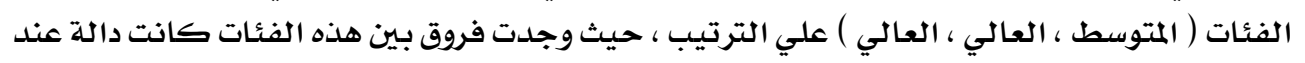

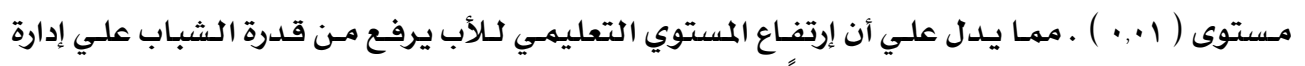

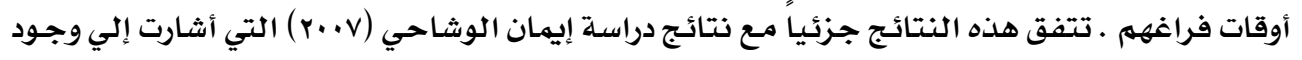

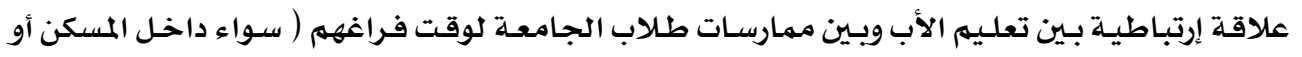

جدول (^) : تحليل التباين بين قدرة الشباب الجامعي علي إدارة أوقات فراغهم

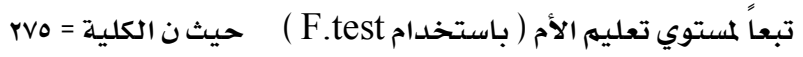

\begin{tabular}{|c|c|c|c|c|c|c|}
\hline مستوى & قيمة ف & متوسط & الحرجة & مجموع المربعات & مصدر التباين & المحاور \\
\hline دالة & $\mathfrak{\xi}, \boldsymbol{Y} \xi$ & $\begin{array}{l}9\{\Psi \cdot, Y \wedge \\
r \mid r, \wedge Y\end{array}$ & $\begin{array}{l}r \\
r Y r \\
r Y \varepsilon\end{array}$ & $\begin{array}{l}119 r \cdot 07 \\
01171,01 \\
r V \cdot 19, \cdot V\end{array}$ & • • بين المجموعات المبائ المجوعات & اـ التخطيط \\
\hline دالة & $\{1,10$ & $\begin{array}{l}\Delta 0 \cdot v, \cdot r \\
11 \varepsilon, r v\end{array}$ & $\begin{array}{l}r \\
r Y r \\
r Y \varepsilon\end{array}$ & $\begin{array}{l}11 \cdot 1 \xi, \bullet Y \\
r \mid 1 \cdot V, \Sigma Y \\
\varepsilon r|r|, 01\end{array}$ & 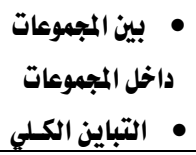 & rـ التنفيذ: \\
\hline دالة & $\Delta \Lambda, q T$ & $\begin{array}{l}1.914,9 . \\
1 \wedge 7,8 .\end{array}$ & $\begin{array}{l}r \\
r Y r \\
r Y \varepsilon\end{array}$ & $\begin{array}{l}\text { rla9r,A. } \\
0.999,11 \\
\text { Vr797,91 }\end{array}$ & 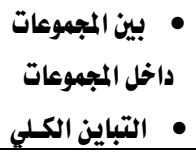 & זـ التقييم \\
\hline دالة & Or, $\cdot r$ & $\begin{array}{l}\text { IVTrv, Tr } \\
1 r \cdot \cdot, 14\end{array}$ & $\begin{array}{l}r \\
r Y r \\
r Y \varepsilon\end{array}$ & 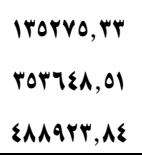 & 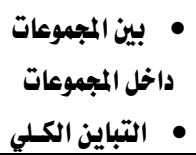 & 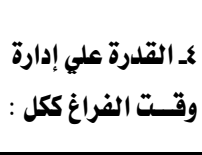 \\
\hline
\end{tabular}

جدول (^) يوضح وجود تفاعل دال إحصائياً بين قدرة الشباب علي إدارة أوقـات فراغهم تبعـاً

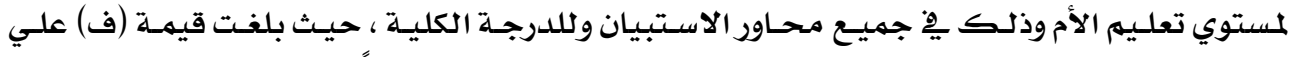

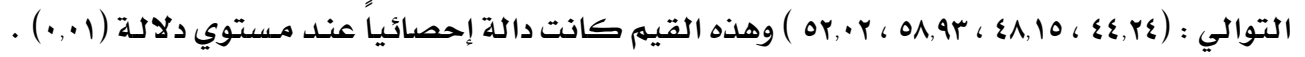

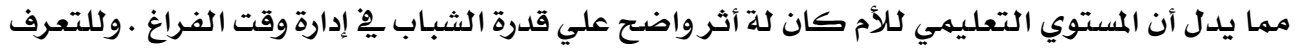

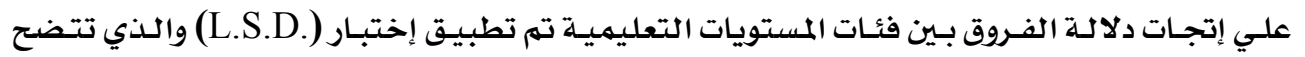

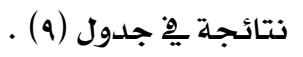


جدول ( ه ) اختبار LSD للمقارنات المتعددة

\begin{tabular}{|c|c|c|c|}
\hline م= צسو, عالي & مت م=وسط & من م=خفض & تعليم الأم \\
\hline & & - & منخفض \\
\hline & - & $*<0,1 \cdot 1$ & متوسط \\
\hline- & $* \nLeftarrow$ rq,VYV & $* * 71, \wedge$, & عالي \\
\hline
\end{tabular}

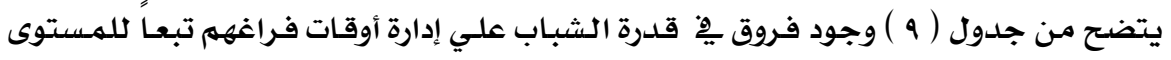

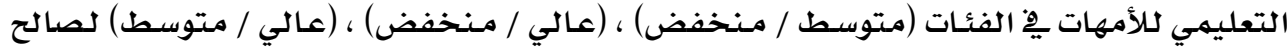

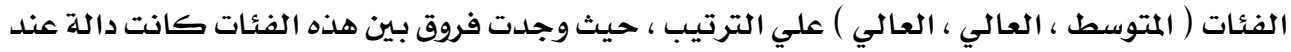

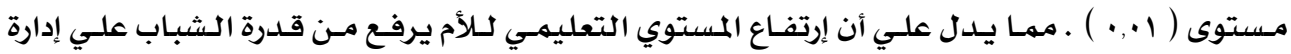

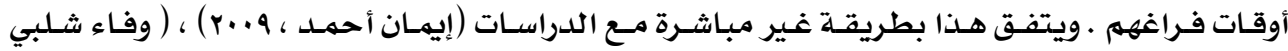

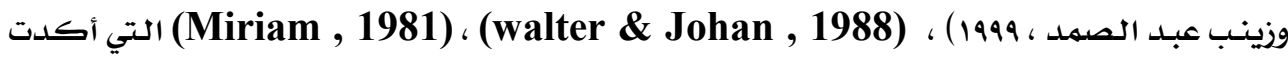

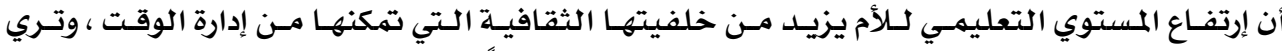

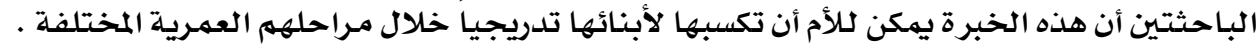
جدول ( • ) : تحليل التباين بين قدرة الشباب الجامعي علي إدارة أوقات فراغهم تبعاً

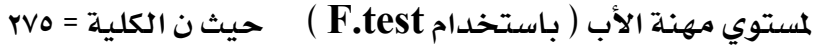

\begin{tabular}{|c|c|c|c|c|c|c|}
\hline مستوى & قيمة ف & متوسط & الحرجات & المجربعات & مصلدر التباين & المحاور \\
\hline دالة & $\{0, r r$ & $\begin{array}{l}\text { Yr.r,Yr } \\
109, Y 1\end{array}$ & $\begin{array}{l}r \\
\text { rYY } \\
\text { rYs }\end{array}$ & $\begin{array}{l}\mid \Sigma Y \cdot 0, \Sigma \varepsilon \\
\varepsilon r\{\varepsilon Y, r Y \\
O \Lambda \cdot \xi Y, Y Y\end{array}$ & • • بين المجموعات التباتين المعوعات & اـ التخطيط \\
\hline دالة & $\{v, \eta\rceil$ & $\begin{array}{l}01 \leqslant 9, A r \\
1+A, 17\end{array}$ & $\begin{array}{l}r \\
\text { rrr } \\
\text { rYs }\end{array}$ & 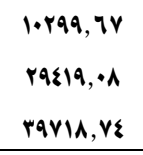 & 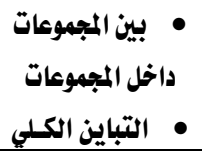 & rـ التنفيذ: \\
\hline دالة & 89,79 & $\begin{array}{l}\text { A^Y乏,० } \\
\mid ₹ \wedge, 7 \Lambda\end{array}$ & $\begin{array}{l}r \\
r Y r \\
r Y \varepsilon\end{array}$ & 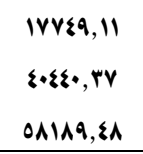 & 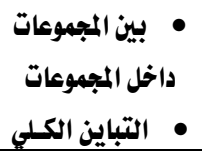 & rـ القييي \\
\hline ال• & $7 \cdot, 17$ & $\begin{array}{l}\text { Tlrol, Tr } \\
1.19, \mathrm{Vr}\end{array}$ & $\begin{array}{l}r \\
r Y r \\
r Y \varepsilon\end{array}$ & $\begin{array}{l}\text { Irrr.r,rs } \\
\text { rrrrry, } 10 \\
\varepsilon \cdots+11,1 \Lambda\end{array}$ & 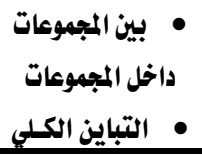 & 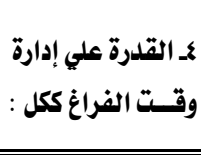 \\
\hline
\end{tabular}


جدول (11 ) اختبار LSD للمقارنات المتعددة

\begin{tabular}{|c|c|c|c|}
\hline م= عليا & مت متوسطة . م90,09 & 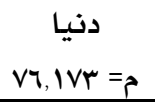 & مهنة الأب \\
\hline & & - & دنيا \\
\hline & - & $* 1_{19, \varepsilon 1 V}$ & متوسطة \\
\hline- & $* *$ ro,rrV & $* 0 \leqslant, \vee 00$ & عليا \\
\hline
\end{tabular}

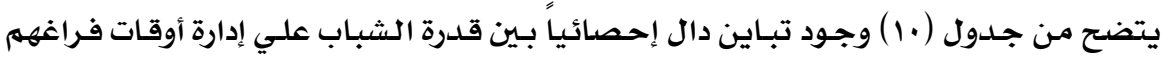

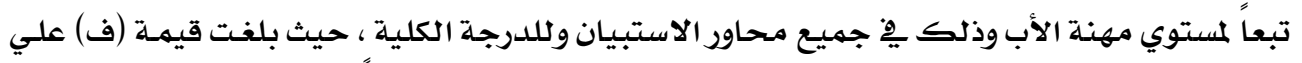

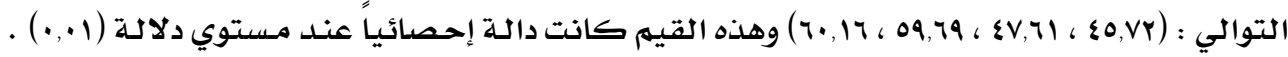

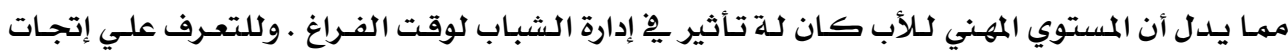

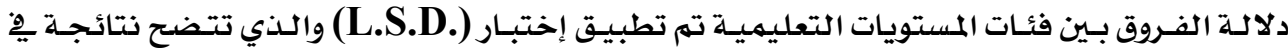

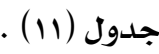

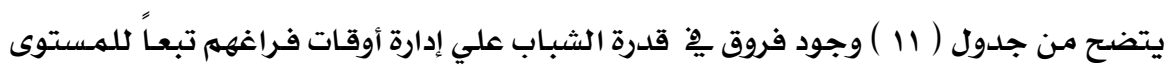

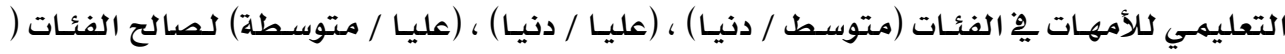

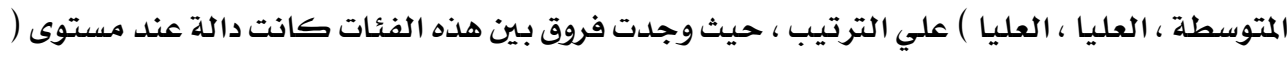

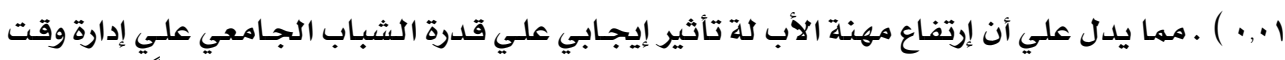

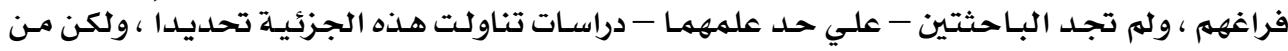

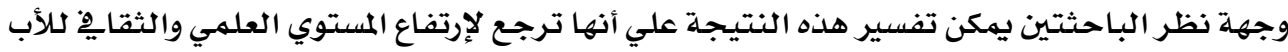

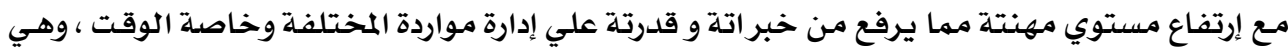
خبر ات يمكنة بالتدريـج أن يكسبها لأبنائة. 


\begin{tabular}{|c|c|c|c|c|c|c|}
\hline \multicolumn{7}{|c|}{ 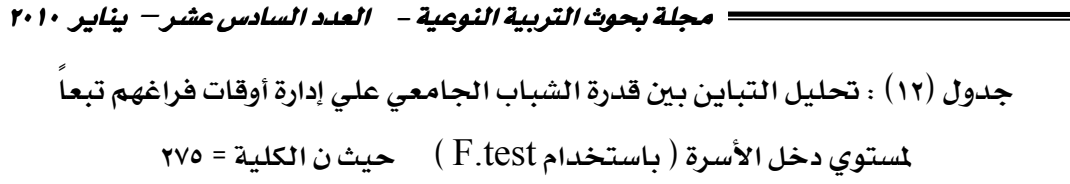 } \\
\hline مستوى الدلالة & فيمة ف) قيمة & متوسط & الحرجية & مجموع المربعات & مصدر التباين & المحاور \\
\hline دالة & $\$ 1, Y \cdot$ & $\begin{array}{l}\text { OYAT, rY } \\
\text { IrV, q\& }\end{array}$ & $\begin{array}{l}r \\
r Y r \\
r Y \varepsilon\end{array}$ & 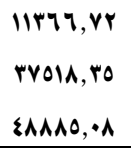 & 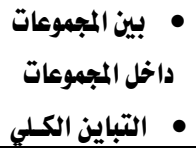 & اــ التخطيط \\
\hline دالة & $\Delta \Lambda, H r$ & $\begin{array}{l}\text { Tors, YY } \\
111, \wedge \Lambda\end{array}$ & $\begin{array}{l}r \\
\text { rYr } \\
\text { rYs }\end{array}$ & $\begin{array}{l}\mid r \cdot\{\Lambda, r \mid \\
r \cdot\{r \mid, 09 \\
\sum r\{\Lambda \cdot, r \mid\end{array}$ & 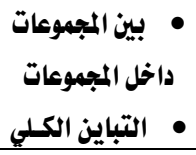 & rـ التنفيذ: \\
\hline دالة & $O r, \wedge O$ & $\begin{array}{l}\text { OrrA, AA } \\
\text { qY, YA }\end{array}$ & $\begin{array}{l}\text { r } \\
\text { rYY } \\
\text { rYs }\end{array}$ & 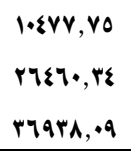 & 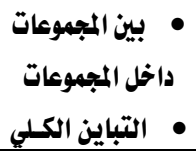 & "ــ القييي \\
\hline دالة & $\Delta q, 7 \&$ & 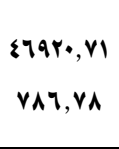 & $\begin{array}{l}r \\
r Y r \\
r Y \xi\end{array}$ & 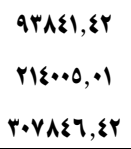 & • • بين المجموعات التباين المعوعات & الفـإاغارة وكل : \\
\hline
\end{tabular}

\begin{tabular}{|c|c|c|c|}
\hline م= مرتفع & م= متوسط 90,9 & منخفض م= & دخل الأسـرة \\
\hline & & - & منخخض \\
\hline & - & $* \mid 1,101$ & متوسط \\
\hline - & $* * r, q \leqslant r$ & $* \& \varepsilon V, 1 \cdot 1$ & مرتفـع \\
\hline
\end{tabular}

جـدول (r ا ) يبـين وجـود تبـاين دال إحصائياً بـين قدرة الشبـاب علـي إدارة أوقـات فـراغهم تبعـاً

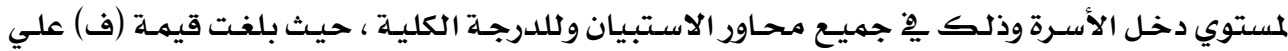

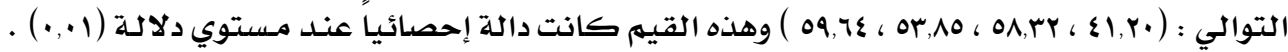

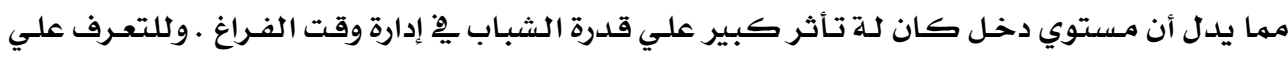

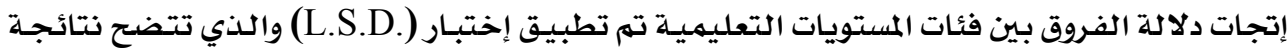

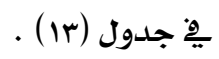

يتضـح من جدول ( r ا ) وجود فروق بين قدرات الشباب علي إدارة وقت فراغهم بين الأسـر ذوي

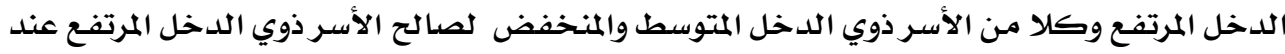

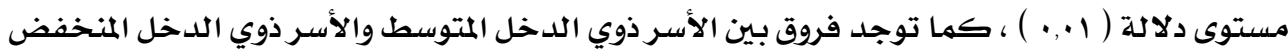

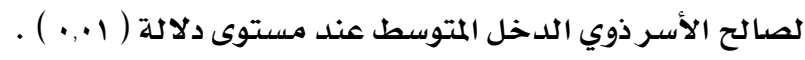


يتفق هـذا جزئيـا مـع (Turner \& Krewski ， 2005) حيـث أشـارا إلي إرتبـاط الحالـة

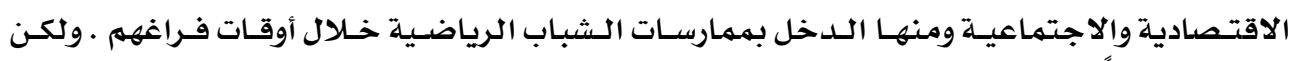

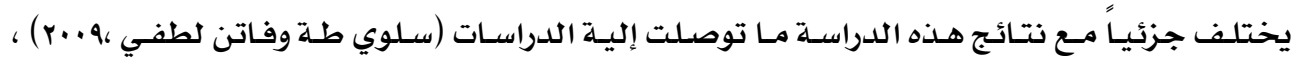

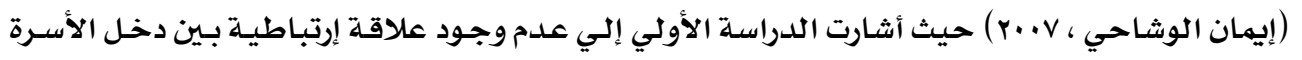

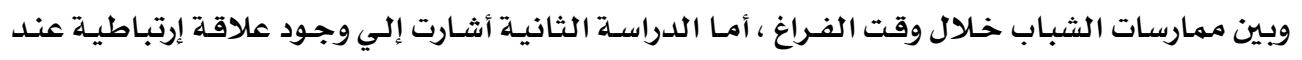

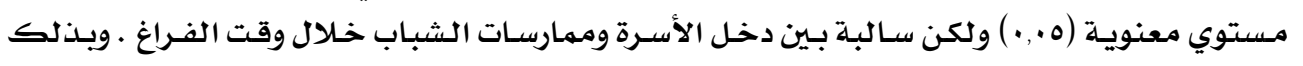

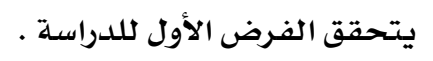

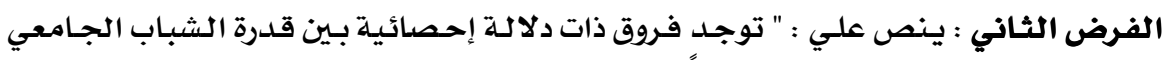

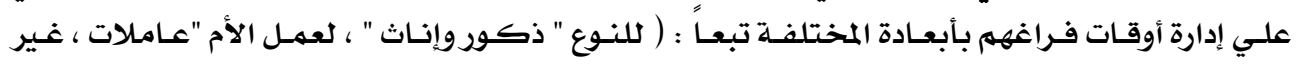

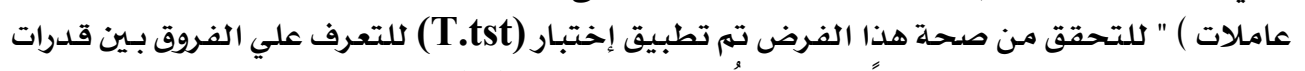

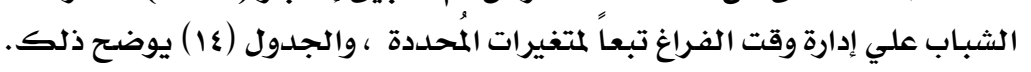

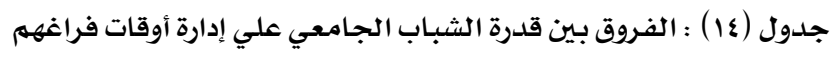

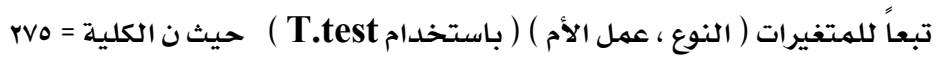

\begin{tabular}{|c|c|c|c|c|c|c|c|c|}
\hline \multirow{2}{*}{ إلدالة } & \multirow{2}{*}{ الدلالة } & \multirow{2}{*}{ "قيهة } & \multirow{2}{*}{ العينة } & \multirow{2}{*}{ المعياري } & \multirow{2}{*}{ الحسابي } & \multicolumn{3}{|c|}{ البيـــــــــان } \\
\hline & & & & & & الفئات & الخصائص & المحاور \\
\hline \multirow{2}{*}{ الإناث } & \multirow{2}{*}{$\cdot, 0$} & \multirow{2}{*}{$r, r \cdot$} & ira & $1 \cdot, \pi r$ & $r r, 70$ & ذكور & \multirow{2}{*}{ النوع } & \multirow{4}{*}{ التخطيط } \\
\hline & & & $1 \& 7$ & $1 \cdot, 0$. & $r 9,09$ & إناث & & \\
\hline \multirow{2}{*}{ العاملة } & \multirow{2}{*}{,, 1} & \multirow{2}{*}{$19,9 \xi$} & 107 & $\mathrm{v}, \hat{\leqslant \Lambda}$ & $\xi r$, ro & عاملة & \multirow{2}{*}{ عمل الأم } & \\
\hline & & & 119 & $0, \Lambda \cdot$ & $r 0, \wedge 0$ & غير عاملة & & \\
\hline \multirow{2}{*}{ الإناث } & \multirow{2}{*}{$\cdot,+1$} & \multirow{2}{*}{$r 1,10$} & $1 r 9$ & $0,7 \pi$ & rI,Ar & ذكور & \multirow{2}{*}{ النوع } & \multirow{4}{*}{ بــ التنفيذ } \\
\hline & & & 187 & $0, \cdot 1$ & $r o, r q$ & إناث & & \\
\hline \multirow{2}{*}{ العاملة } & \multirow{2}{*}{$\bullet, 0$} & \multirow{2}{*}{$r$, rA } & 107 & $A, r V$ & $r \cdot, 0$ & عاملة & \multirow{2}{*}{ عمل الأم } & \\
\hline & & & 119 & $\Lambda, \wedge 9$ & $r Y, T A$ & غير عاملة & & \\
\hline \multirow{2}{*}{ الإناث } & \multirow{2}{*}{$\bullet,+1$} & \multirow{2}{*}{ ro, 91} & 189 & $7, \cdot r$ & $r \cdot, \cdot 0$ & ذكور & \multirow{2}{*}{ النوع } & \multirow{4}{*}{ זـــ التقييه } \\
\hline & & & 187 & $7, \& \%$ & $\varepsilon 9,7 \xi$ & إناث & & \\
\hline \multirow{2}{*}{ العاملة } & \multirow{2}{*}{$\bullet, \bullet 1$} & \multirow{2}{*}{$17, \xi Y$} & 107 & $\Lambda, \xi \bullet$ & $\leqslant v, \eta$. & عاملة & \multirow{2}{*}{ عمل الأم } & \\
\hline & & & 119 & $\Lambda, \cdot \boldsymbol{r}$ & $r 1, \bullet \wedge$ & غير عاملة & & \\
\hline \multirow{2}{*}{ الإناث } & \multirow{2}{*}{,, 1} & r. & 179 & 17,71 & A0,or & ذكور & (1) & كـــ إدارة \\
\hline & & & $1 \leqslant 7$ & $10,2 \mathrm{r}$ & $|r|, \pi r$ & إناث & . & وقت \\
\hline a & & & 107 & $10,1 \xi$ & $\mid r \cdot, \cdot \cdot$ & عاملة & & الفراغ \\
\hline |⿱一⿻上丨⿱⿰㇒一乂 & , & 17,76 & 119 & $|r, \Delta|$ & $\wedge \varepsilon, \eta$ & غير عاملة & משרוt & ككل \\
\hline
\end{tabular}




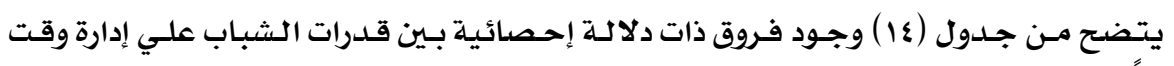

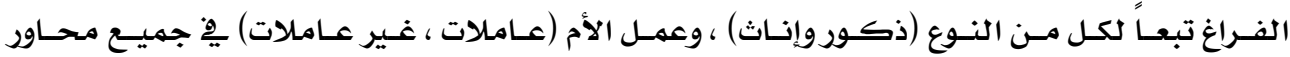

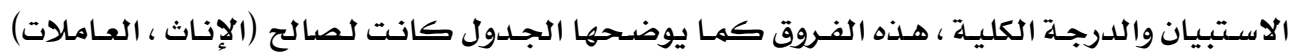

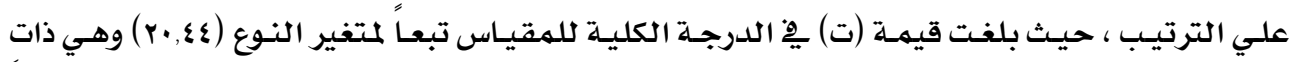

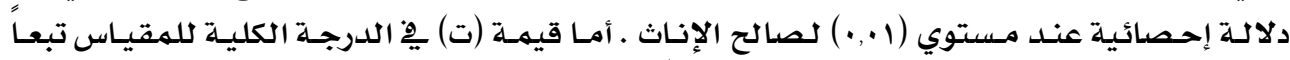

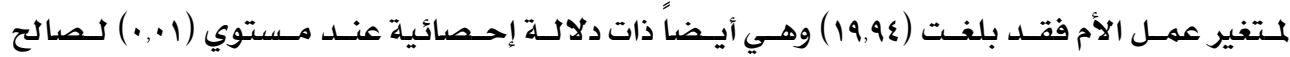

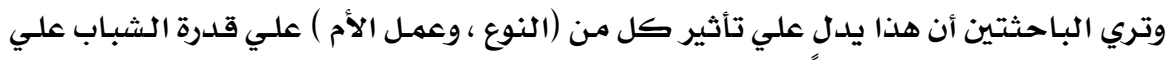

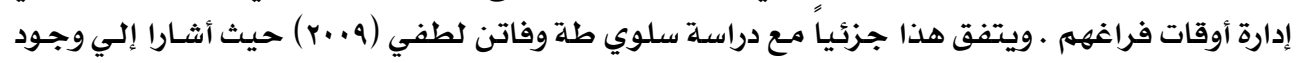

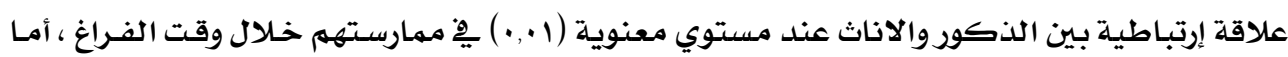

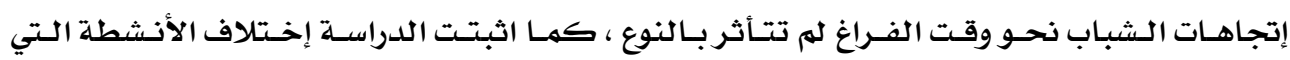

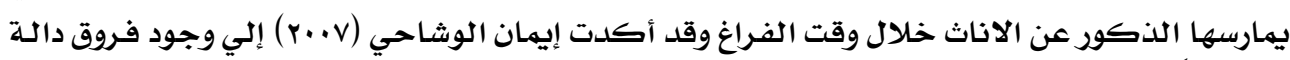

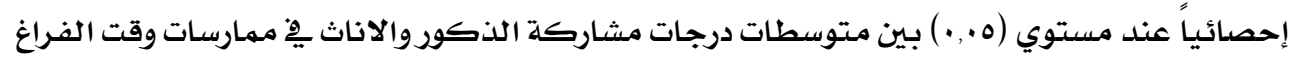

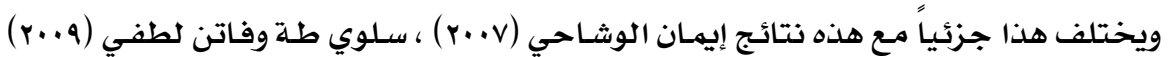

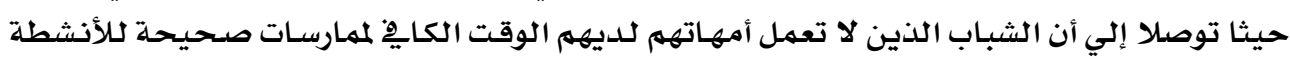

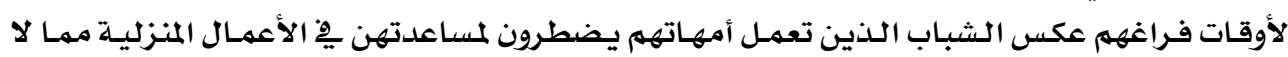

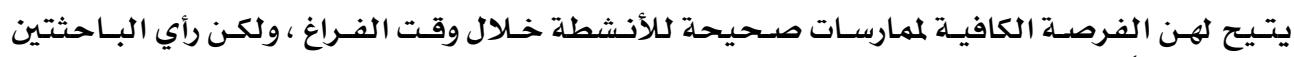

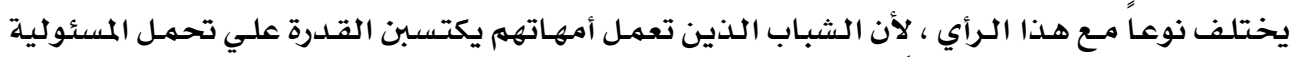

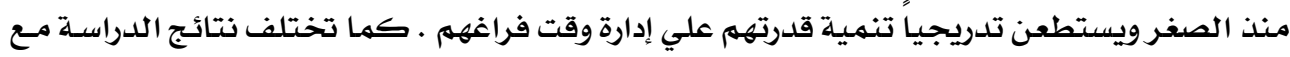

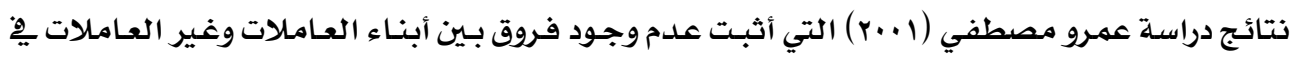

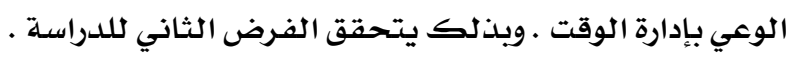

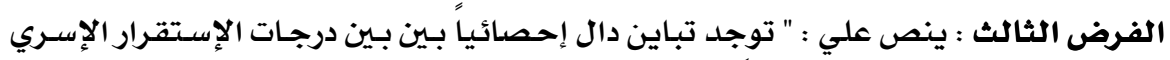

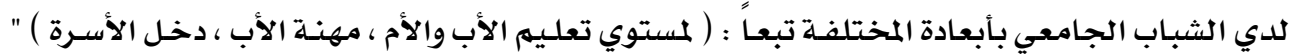

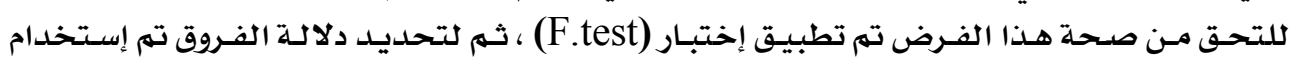

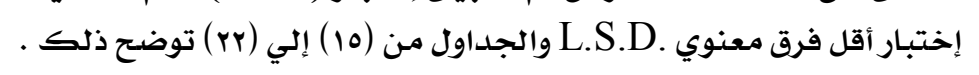

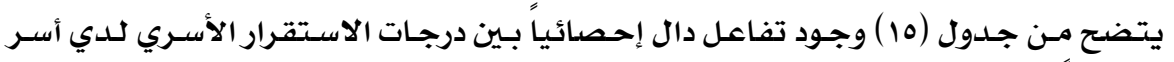

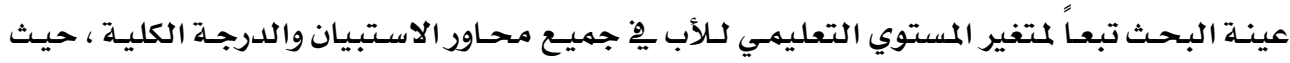

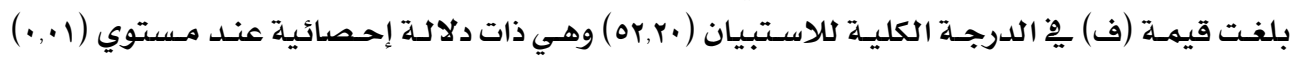

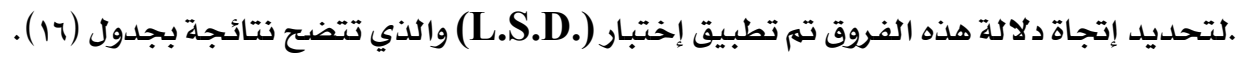

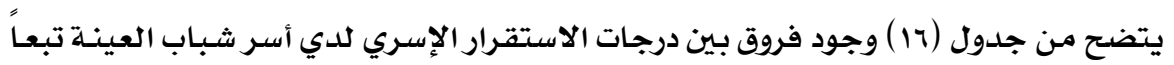

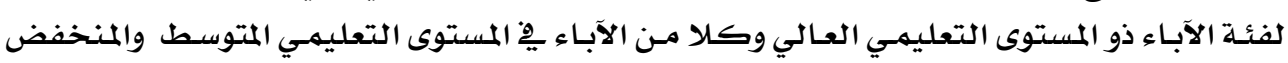

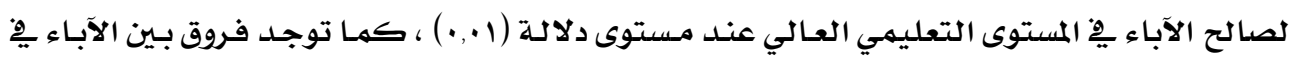


المستوى التعليمي المتوسط والآباء ِِِ المستوى التعليمي المنخفض لصالح الآباء ِِِ المستوى التعليمي المتوسط عند مستوى دلالة ( ا.,. ) ) . جدول (10) : تحليل التباين بين درجات الإستقرار الأسري لدي الشباب الجامعي

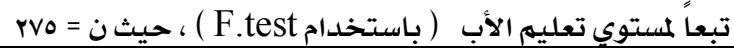

\begin{tabular}{|c|c|c|c|c|c|c|}
\hline مستوى & قيمة ف & متوسط & الحرجية & مجموع & مصدر التباين & الفئات \\
\hline دالة & $\varepsilon r, \xi \Lambda$ & $\begin{array}{l}\text { Ir.r,rr } \\
r Y, T Y\end{array}$ & $\begin{array}{l}r \\
r Y r \\
r Y \varepsilon\end{array}$ & 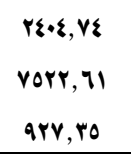 & • • بين المجموعات التجباين الكلي & الاجتماعية للأسرة \\
\hline دالة, & $r \xi, r V$ & $\begin{array}{l}799 r, r r \\
r \cdot \xi, 11\end{array}$ & $\begin{array}{l}r \\
r Y r \\
r Y \varepsilon\end{array}$ & 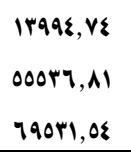 & 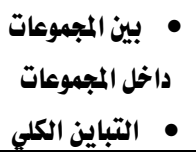 & 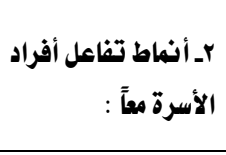 \\
\hline 1 اי,• & or, r. & $\begin{array}{l}\text { Ir-\&r, Ir } \\
r \leqslant q, A r\end{array}$ & $\begin{array}{l}r \\
r Y r \\
r Y \varepsilon\end{array}$ & $\begin{array}{l}r q \cdot \wedge \varepsilon, r Y \\
7 \vee q 7 \xi, \wedge Y \\
9 \xi \cdot \xi 9,11\end{array}$ & 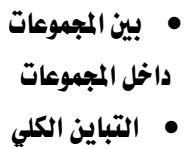 & ككل: الاستقرار الأسري \\
\hline
\end{tabular}

جدول (1 ا ) اختبار LSD للمقارنات المتعددة

\begin{tabular}{|c|c|c|c|}
\hline 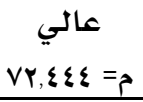 & مت متوسط ... مr.q7 & منشخفض & تعليهم الأب \\
\hline & & - & منـخفض \\
\hline & - & * & متتوسط \\
\hline- & $* 4,0 \leqslant \varepsilon$ & $* *$ YO,VTA & عالي \\
\hline
\end{tabular}

يتضـح مـن جــدول (IV) ) وجـود تفاعل دال إحـصائياً بـين درجـات الاستقـرار الأسـري لـدي أسـر

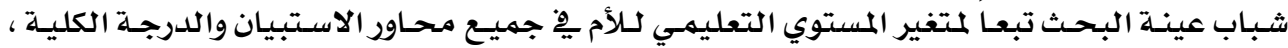

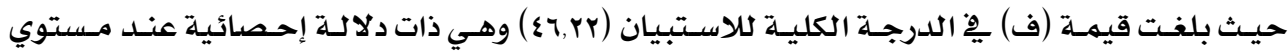

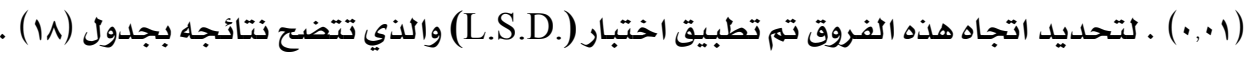
يتضح من جدول (1) ) وجود فروق بين درجات الاستقرار الأسـري لدي أسر شبـاب العينـة تبعاً

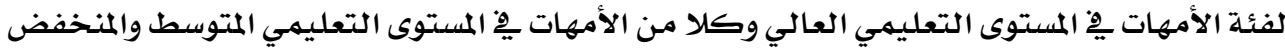

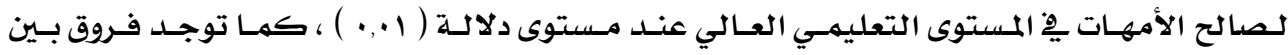

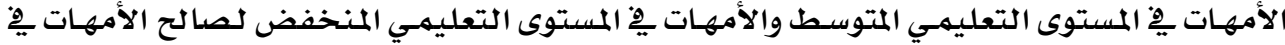
المستوى التعليمي المتوسط عند مستوى دلالة ( ه.,. ) . 


\begin{tabular}{|c|c|c|c|c|c|c|}
\hline مستوى & قيمة ف & متوسط & درجات & مجموع المربعات & مصلدر التباين & الفئات \\
\hline دالة & or,o. & $\begin{array}{l}r \cdot 0, \cdot r \\
1 r, 11\end{array}$ & $\begin{array}{l}\text { r } \\
\text { rrr } \\
\text { rrs }\end{array}$ & $\begin{array}{l}|\Sigma| \cdot, \cdot 0 \\
\text { rOA\&, YY } \\
\Sigma 99 \xi, Y Y\end{array}$ & 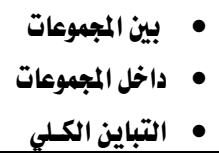 & الاجتماعية للأسرة الحياة \\
\hline دالة & $\varepsilon q, r q$ & $\begin{array}{c}19 \Lambda 7 \gamma, \xi \Lambda \\
\xi . r, 0 \xi\end{array}$ & $\begin{array}{l}\text { r } \\
\text { rrr } \\
\text { rYs }\end{array}$ & $\begin{array}{l}\text { rarrs, 97 } \\
1.9 \& 9 \cdot, r r \\
\text { 1\&9Yro, } 19\end{array}$ & 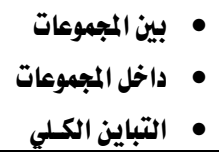 & $\begin{array}{r}\text { rـ أنهاط تفاعل أفراد } \\
\text { الأسرة معاً: }\end{array}$ \\
\hline دالة & $\{7, r Y$ & $\begin{array}{l}\text { YY\&qY,•^ } \\
\text { O१\&,YY }\end{array}$ & $\begin{array}{l}\text { r } \\
\text { rrr } \\
\text { rrs }\end{array}$ & $\begin{array}{l}\text { O\&qAs,17 } \\
\text { I7IVYA, Tr } \\
\text { riqrYr,Yq }\end{array}$ & 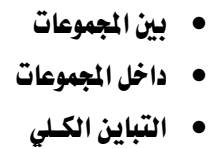 & ككل: كـالاستقرار الأسري \\
\hline
\end{tabular}

جدول (1) اختبار LSD للمقارنات المتعدددة

\begin{tabular}{|c|c|c|c|}
\hline 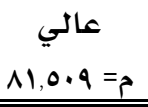 & $\begin{array}{l}\text { متوسط } \\
\text { م=Y.\&.V }\end{array}$ & 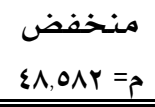 & تعليه الأم \\
\hline & & - & منخفض \\
\hline & - & $\& r, \wedge r \varepsilon$ & متتوسط \\
\hline- & $* * r q, 1 \cdot r$ & $* *$ rY,QYY & عالي \\
\hline
\end{tabular}

يتضـح مـن جـدول (19) )وجـود تفاعل دال إحـصائياً بـين درجـات الاستقـرار الأسـري لـدي أسـر

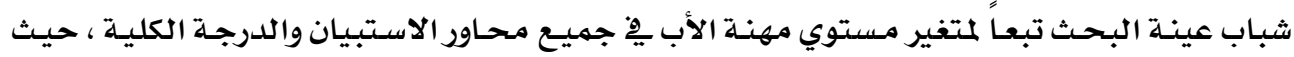

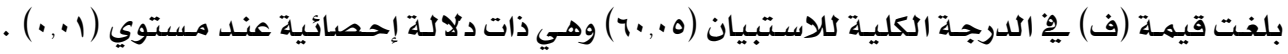

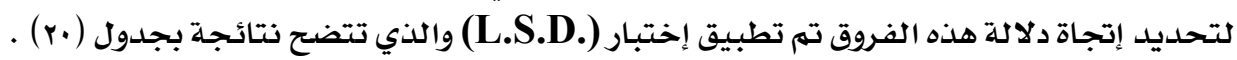
يتضـح من جدول ( • ) وجود فروق يِ درجات الاستقرارالأسـري بـين أسـر العينـة لفئـات الآبـاء

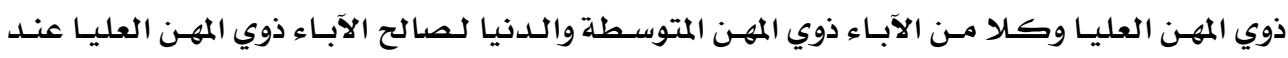

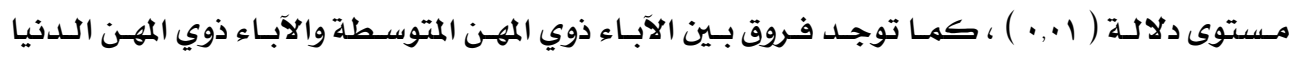

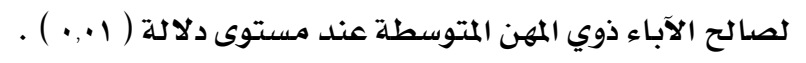


جدول (19) : تحليل التبـاين بين درجات الإستقرار الأسري لدي الشباب الجامعي

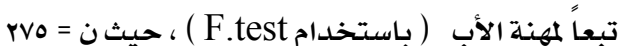

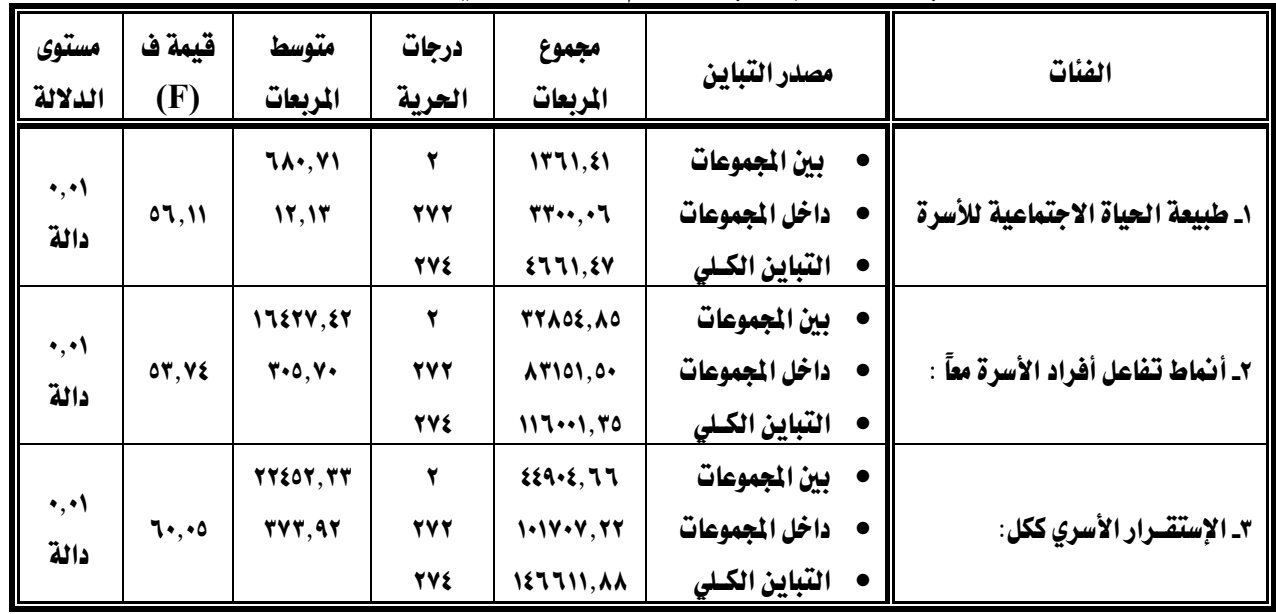

جدول ( • إختبار LSD للمقارنات المتعلددة

\begin{tabular}{|c|c|c|c|}
\hline مليا & 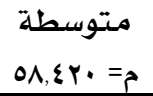 & دنيا & مهنـة الأب \\
\hline & & - & دنيا \\
\hline & - & $* *$ ir, IN. & متوسطة \\
\hline - & $* 19,9 \leq 0$ & * * * וr & عليا \\
\hline
\end{tabular}

يتضح مـن جـدول (Y) وجـود تفاعل دال إحصائياً بـين درجـات الاستقرار الأسـري لدي أسـر

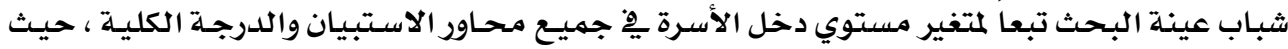

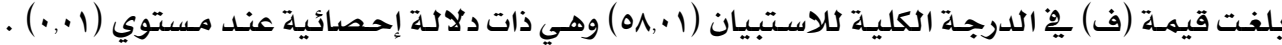

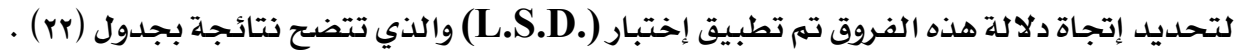

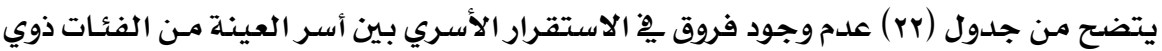

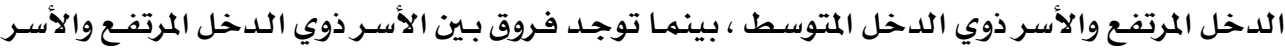

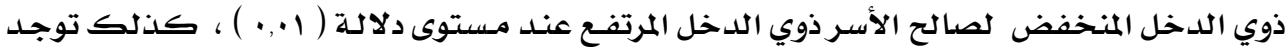

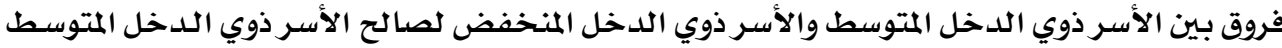

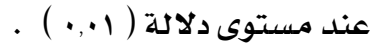




\begin{tabular}{|c|c|c|c|c|c|c|}
\hline & \multicolumn{6}{|c|}{ 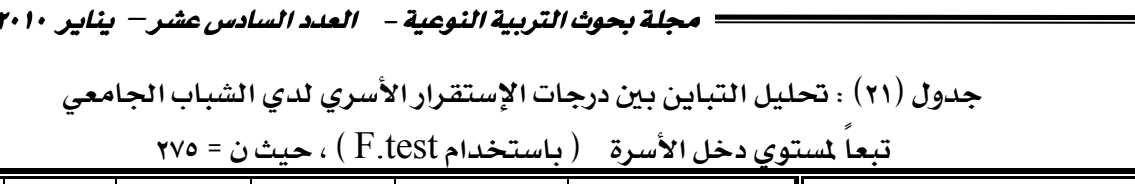 } \\
\hline مستوى & $\begin{array}{c}\text { قيمة ف } \\
\text { (F) } \\
\end{array}$ & متوسط & الحرجية & مجموع المربعات & مصلدر التباين & الفئات \\
\hline دالة & $\Delta 0,7 \varepsilon$ & $\begin{array}{l}|\Sigma q|, 71 \\
r q, \wedge \mid\end{array}$ & $\begin{array}{l}\text { r } \\
\text { rYY } \\
\text { rYs }\end{array}$ & $\begin{array}{l}\text { raAt, rr } \\
\text { rrar,AY } \\
\text { l.rYY,rr }\end{array}$ & 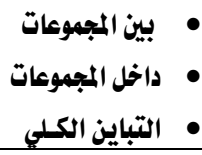 & لـأــبيعة الحياة الاجتماعية \\
\hline دالة & $\Sigma \eta, r q$ & $\begin{array}{l}A Y \wedge q, 1 \xi \\
1 \wedge 9,\{q\end{array}$ & $\begin{array}{l}\text { r } \\
\text { rrr } \\
\text { rYE }\end{array}$ & $\begin{array}{l}\text { IVOYa, YA } \\
0105 \cdot, 11 \\
791 \% \cdot, 17\end{array}$ & 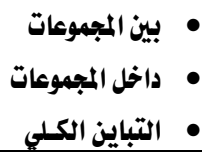 & معـ أنهاط تفاعل أفراد الأسرة \\
\hline دالب & $0 \Lambda, \cdot 1$ & $\begin{array}{l}\left|\sum T\right| r, A \cdot \\
\text { rOI, Q. }\end{array}$ & $\begin{array}{l}\text { r } \\
\text { rYr } \\
\text { rYs }\end{array}$ & $\begin{array}{l}\text { rarro, 09 } \\
\text { 71017,9. } \\
\text { qrrsr, } \$ 9\end{array}$ & 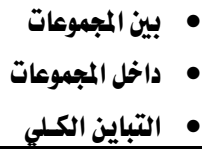 & זـ_ الاستقرار الأسري ككل: \\
\hline
\end{tabular}

جدول (r (r) اختبار LSD للمقارنات المتعددة

\begin{tabular}{|c|c|c|c|}
\hline م= مرتفع & مت متوسط & منتخفض & دخل الأسرة \\
\hline & & - & منخفض \\
\hline & - & $* *$ Yo, $\wedge \cdot 1$ & متوسط \\
\hline- & r,vos & $* \& Y Y, \cdot \sum Y$ & مـرتفع \\
\hline
\end{tabular}

يتضح مما سبتق تأثير المتغيرات ( مستوي تعليهم الوالدين ، مهنـة الأب ، دخل الأسـرة ) علسي

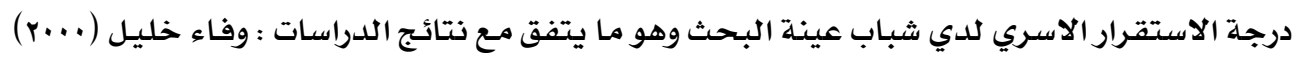

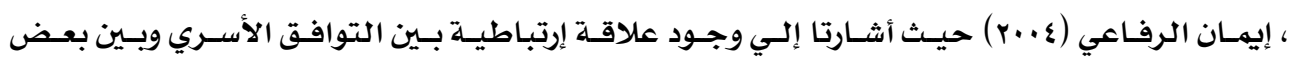

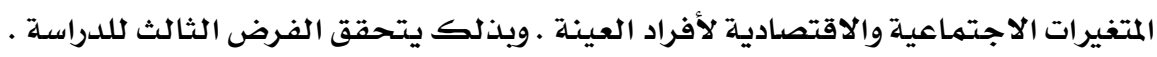
الفرض الرابع : ينص علي : " توجد فروق ذات دلالة إحصائية بين درجات الإستقرار الإسري

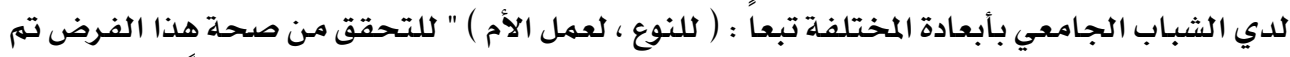

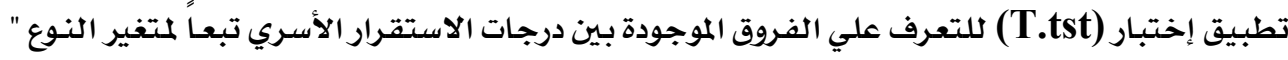

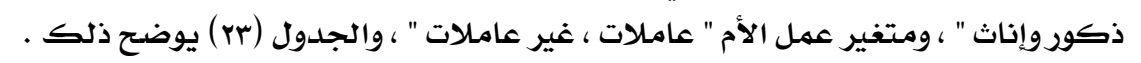


جدول (rr) :الفروق بين درجات الاستقرار الأسـري لدي الشبـاب الجامعي

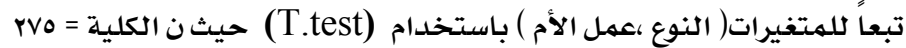

\begin{tabular}{|c|c|c|c|c|c|c|c|c|}
\hline \multirow{2}{*}{ التجاه } & \multirow{2}{*}{ مستوي } & \multirow{2}{*}{ "قيمة } & \multirow{2}{*}{ العينة } & \multirow{2}{*}{ الانحراف } & \multirow{2}{*}{ المتوسط } & \multicolumn{3}{|c|}{ البيــــــــان } \\
\hline & & & & & & الفئات & الخصائص & المحاور \\
\hline \multirow{2}{*}{ الإناث } & \multirow{2}{*}{$\cdot, \cdot 1$} & \multirow{2}{*}{ IA, OV } & 179 & $r, \cdot r$ & 9,01 & ذكور & \multirow{2}{*}{ النوع } & \multirow{4}{*}{ 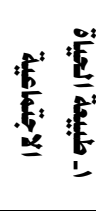 } \\
\hline & & & 157 & $r, r$. & $10,7 \varepsilon$ & إناث & & \\
\hline \multirow{2}{*}{ العاملة } & \multirow{2}{*}{$\cdot, \cdot 1$} & \multirow{2}{*}{$11, r 9$} & 107 & $r, 01$ & $\mid \varepsilon, Y \wedge$ & عاملة & \multirow{2}{*}{ عمل الأم } & \\
\hline & & & 119 & r,Y\& & $1 \cdot, 1 r$ & غير عاملة & & \\
\hline \multirow{2}{*}{ الإناث } & \multirow{2}{*}{$\bullet,+1$} & \multirow{2}{*}{19,09} & 189 & V,or & $r v, r q$ & ذكور & \multirow{2}{*}{ النوع } & \multirow{4}{*}{ 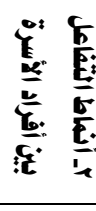 } \\
\hline & & & $1 \varepsilon 7$ & Ir, r. & 71,71 & إناث & & \\
\hline \multirow{2}{*}{ العاملة } & \multirow{2}{*}{$\cdot, \cdot 0$} & \multirow{2}{*}{$r, 11$} & 107 & $10,+1$ & $01,9 \xi$ & عاملة & \multirow{2}{*}{ عمل الأم } & \\
\hline & & & 119 & $17, \times 7$ & $\xi \vee, \wedge \Lambda$ & غير عاملة & & \\
\hline \multirow{2}{*}{ الإناث } & \multirow{2}{*}{$\bullet, \cdot 1$} & \multirow{2}{*}{$r 0,91$} & 179 & $9,1 r$ & $\Sigma \eta, \vee \vee$ & ذ ذكور & \multirow{2}{*}{ النوع } & \multirow{4}{*}{$\sum_{\substack{n \\
0}}^{c}$} \\
\hline & & & 157 & $1\{, 77$ & vv, ro & إناث & & \\
\hline \multirow{2}{*}{ العاملة } & \multirow{2}{*}{$\cdot, \cdot 1$} & \multirow{2}{*}{$\xi, Y \Psi$} & 107 & $17,1$. & $97, \mathrm{VY}$ & عاملة & \multirow{2}{*}{ عمل الأم } & \\
\hline & & & 119 & IV, IV & $0 \Lambda,+1$ & غير عاملة & & \\
\hline
\end{tabular}

يتضـح مـن جـدول (rr ) وجـود فروق ذات دلالـة إحصدائية بـين درجـات الاسـتقرار الأسـري للدي

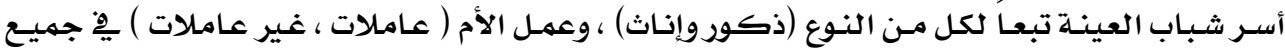

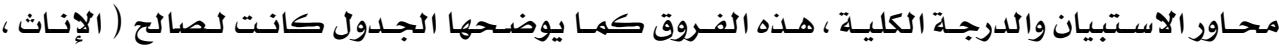

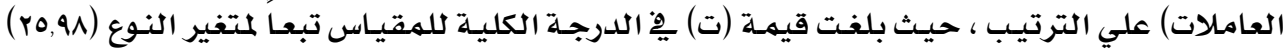

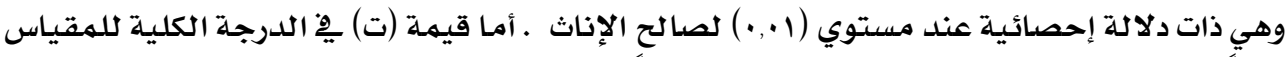

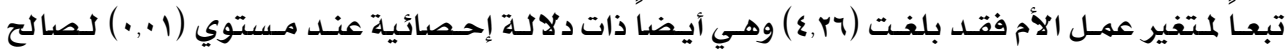
العاملات .

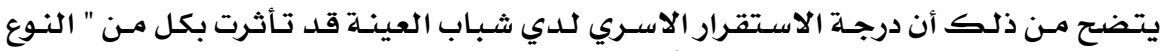

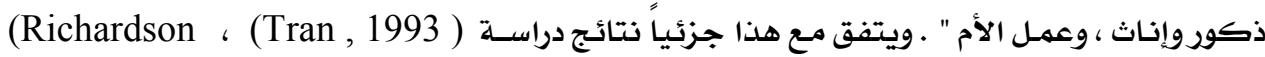

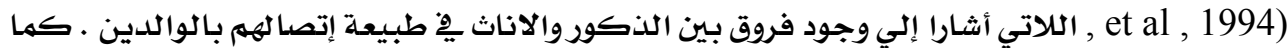

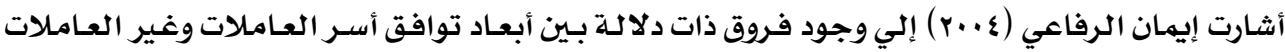

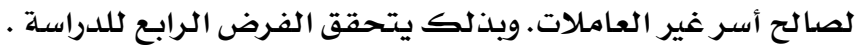

الفرض الخامس : ينص علي : " توجد علاقة إرتباطية بين المتغيرات الديموجرافية للشباب

الجامعي وبين قدرتهم علي إدارة أوقات فراغهم بأبعادة ، وبين درجـة الاستقرار الأسـري للديهم بأبعـادة ". للتحقق من صحة هذا الفرض تم حسـاب معامل إرتباط بيرسون للتحقق من العلاقات الارتباطية بـين

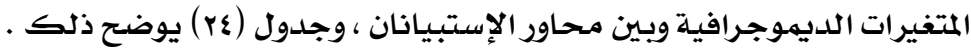




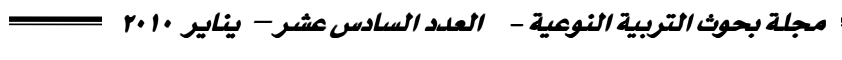

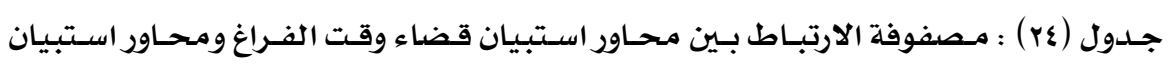

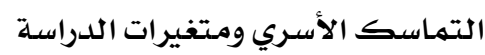

\begin{tabular}{|c|c|c|c|c|c|c|c|}
\hline الأسري ككل التماسك & السلوكي & الاجنماعي & وقت الفراغ ككل & التقييي & التنفيذ & التخطيط & المتفيرات \\
\hline$\cdot, 107$ & - YrY & r7ו, & $\cdot, 1 Y 9$ & $\cdot, r \cdot 1$ & $\cdot, I V A$ & $\cdot, 1 \cdot r$ & الجنس \\
\hline$* * \cdot \wedge Y Y$ & $* * \cdot$, v 0 & $* * \cdot, \mathrm{VV \Lambda}$ & $* * \cdot$ V^ & * • TY & ו ו • • • & $* *$ *, 170 & السن \\
\hline$* * \cdot \wedge q \vee$ & $* * \cdot, \mathrm{V} / 1$ & $* *, \wedge \Sigma Y$ & $* * \cdot V \cdot r$ & & $* *, q r \varepsilon$ & $*$ * var & تعليي الاب \\
\hline$* * \cdot$ V97 & $* \cdot 7 \cdot 7$ & $* * \cdot 9 \leqslant Y$ & $* *$, vro & $* * \cdot 791$ & $* *, V Y \varepsilon$ & * * . N & تعليي الام \\
\hline$* *, \wedge r \varepsilon$ & $* * \cdot v \cdot 9$ & $* *, \wedge \wedge$ & $* * \cdot$ VIV & $* * \cdot 1 \cdot 0$ & $* * \cdot 9 \cdot 1$ & $* * \cdot$, , OV & مهنة الاب \\
\hline$\cdot, r \leqslant \varepsilon$ &., 171 & $\cdot, I r \varepsilon$ & $\cdot, Y 10$ & ד & $\cdot 1 \cdot 1$ & • & عمل الام \\
\hline r., &., 101 & $\cdot, Y \mid r$ & $\cdot 1 \cdot \varepsilon$ & $\cdot, 1 v 0$ &., 199 & rIr, & عدد افراد الاسرة \\
\hline$\cdot, 1 \wedge V$ & $\cdot, 1 \leqslant 0$ & - YrV & $* *, \wedge \cdot \varepsilon$ & rr, • * & $* *, V 71$ & $* * \cdot$, vлr & دخل الاسرة \\
\hline
\end{tabular}

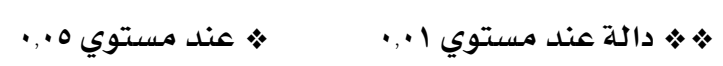

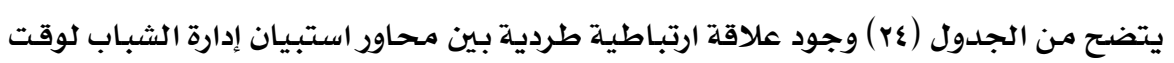

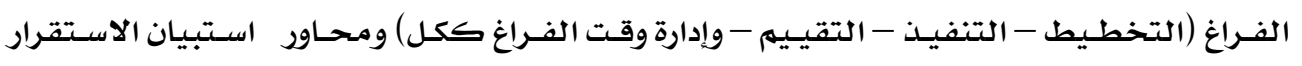

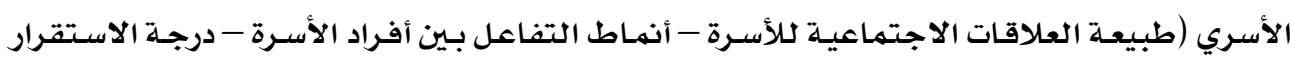

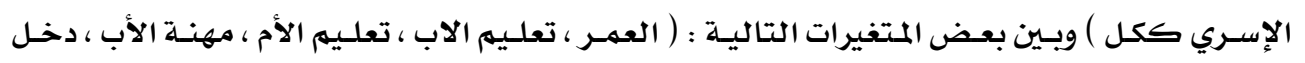

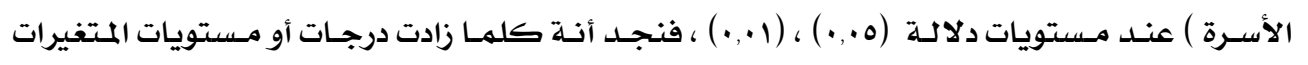

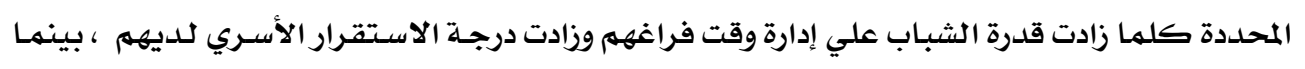

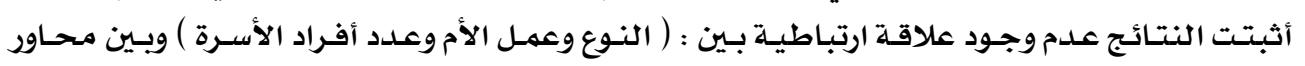

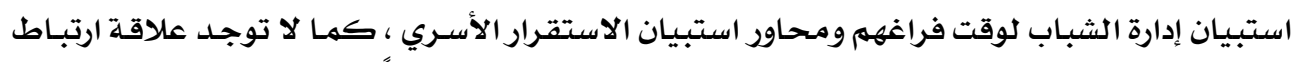

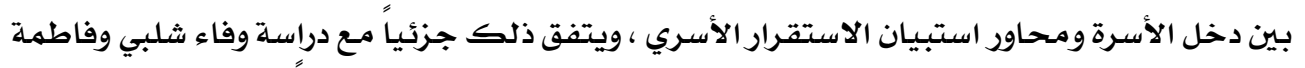

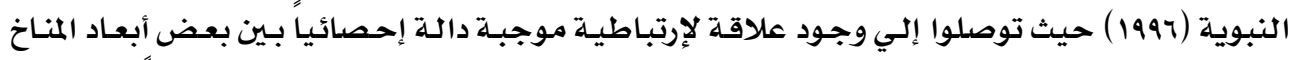

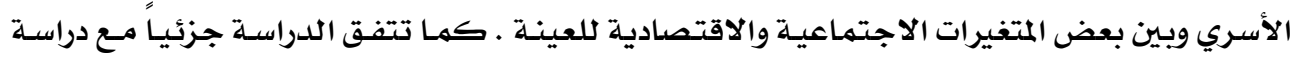

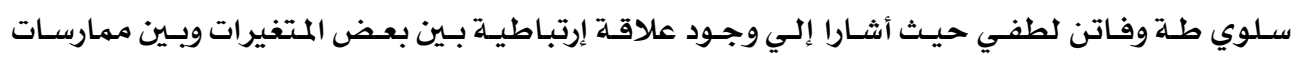

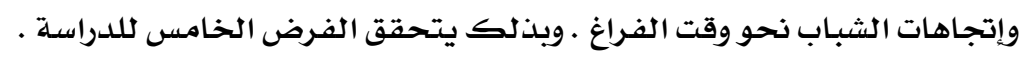

الفـرض السادس : يـصـ علسي : " توجـــ علاقـة إرتبـاطيـة بـين قدرة الشبـاب علسي إدارة أوقـات

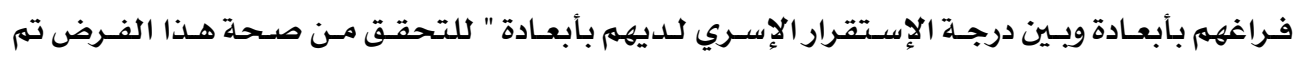

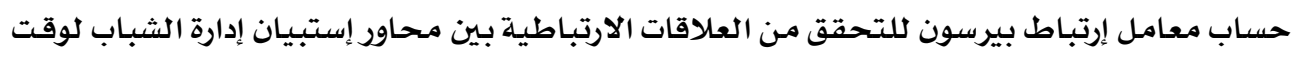

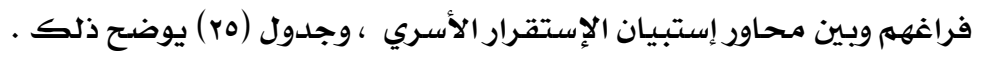


جدول (0r ) : مصفوفة معامل الارتباط بين كل من إدارة الشبـاب لأوقات فراغهم بأبعادة المختلفة وبين درجات التماسك الأسري لديهم بأبعادة

\begin{tabular}{|c|c|c|c|}
\hline التماسك الأسـري & أنماط التفاعل بين & طبيعة العالاقات & المتغيرات \\
\hline$* *$, ^Vo & $* * .91 \mathrm{~V}$ & $* * \cdot \vee \wedge \mathrm{Q}$ & التخطيط \\
\hline$* * \cdot, \cdot 1$ & $* * \cdot \Lambda 1 r$ & $* * 9 \cdot 9$ & التتفيذ \\
\hline$* * \cdot, \wedge \top \Lambda$ & $* *$, vor & $* * \cdot \vee \wedge \mathrm{T}$ & التقييم \\
\hline$* * \cdot, \wedge \varepsilon 0$ & $* * \cdot, \mathrm{VVr}$ & $* * \cdot \Lambda Y I$ & إدارة وقت الفراغ ككل \\
\hline
\end{tabular}

يتضـح من الجدول (0) وجود علاقة ارتبـاطية طردية بـين محاور استبيان إدارة الشبـاب لوقت

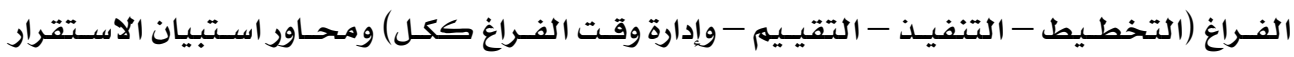
الأسري (طبيعـة العلاقـات الاجتهماعيـة لكلأسـرة - أنهـاط التفاعل بـين أفراد الأسـرة - درجـة الاستقرار

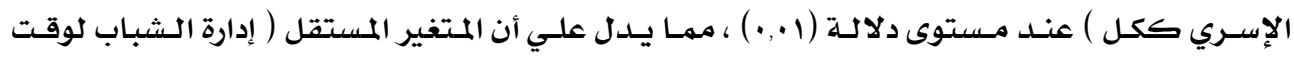

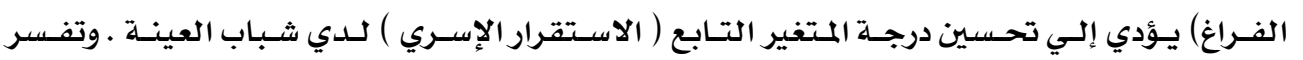
البـاحثتين ذلك بسبـب أن الشبـاب مـع زيـادة قدرتهم وخبر تهم مِ إدارة أوقات فـراغهم يزيــ مـن فاعليـة

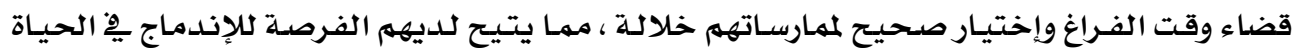
الاجـتماعيـة لكلأسـرة وكذلك التفاعل الايجابي مـع بـاقي أفراد أسرتة ، وهـو مـا يؤدي إلـي إرتفـاع درجـة الاستقرار الإسـري الهاء

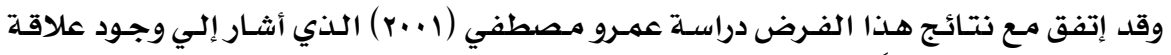

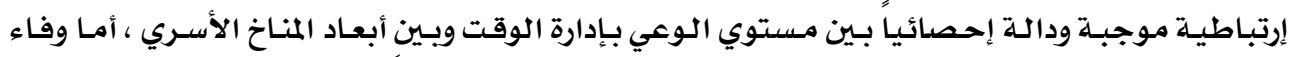

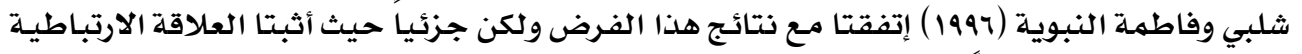

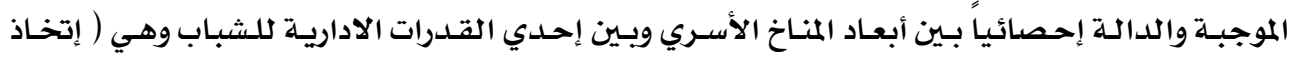

$$
\text { القرار ) . وبذلك يتحقق الفرض السـادس للدراسلة . }
$$

$$
\text { : }
$$

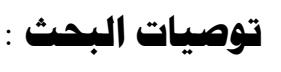

• اهتمام المؤسسـات التربويـة والاجتماعيـة المختلفـة ( المدارس ، الجـامعـات ، الأنديسة الاجتماعيـة ،

دور العبـادة .....) بتوعيـة الشبـاب بـالطرق الـصحيحـة أو الممارسـات الفاعلـة خـلال وقـت الفـراغ

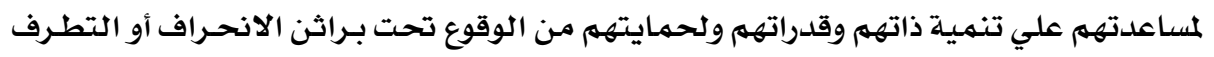

$$
\text { • من خلال المواد الثقافيـة أو التعليميـة المقدمـة . }
$$

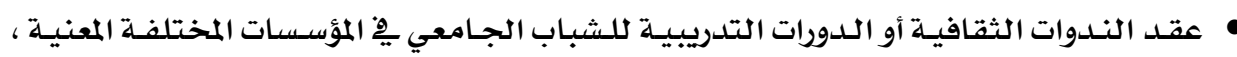

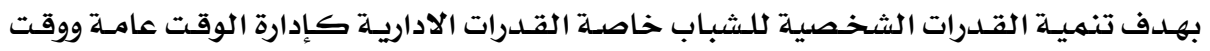

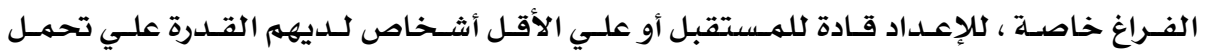

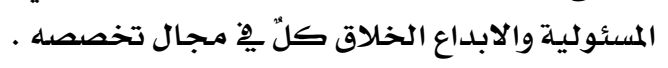


•إلزام الجهات الاعلامية المختلفة بخطة إعلاميـة لها رسـالة هادفة وبنائـة تسـاعد علسي : " قضاء أوقـات ترفيهيـة أسـرية خـلال أوقـات الفـراغ تخلـق منـاخ أسـري صـحي - تـوفر أفكار متعـددة أمـام

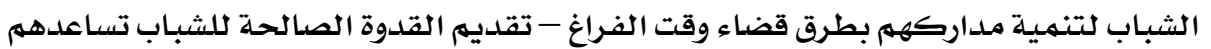

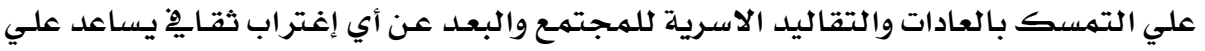

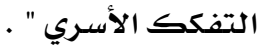

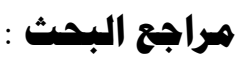

أولاً : المراجع العربية :

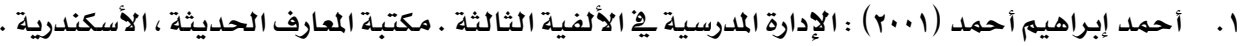

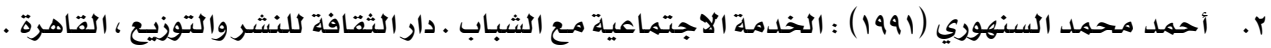

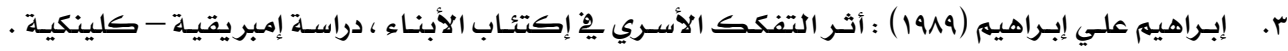

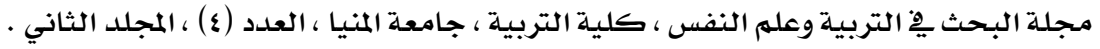

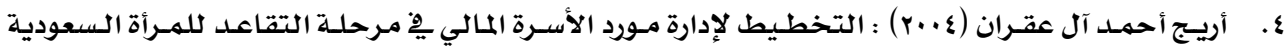
العاملة يْ محافظة جدة ـ رسالة ماجستير غير منشورة ، كلية التربيـة للاقتصاد المنزلي والتربيـة الفنيـة بجدة .

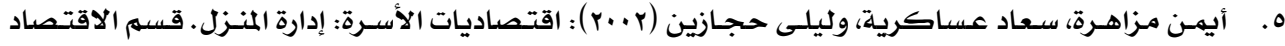

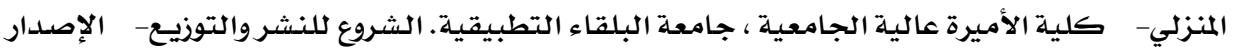
الأول- الطبعة العربية الأولى- الأردن.

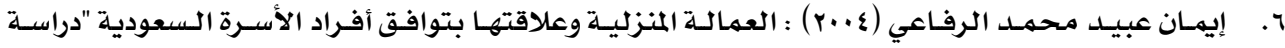
ميدانية بمنطقة مكسة المكرمـة " . رسـالة ماجستير غير منشورة ، قسم السكن وإدارة المنزل ، كليـة التربية

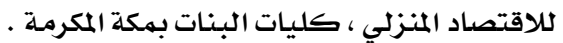

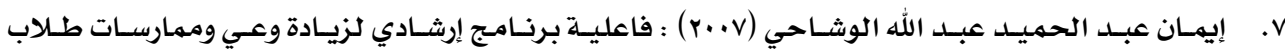

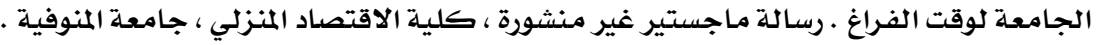

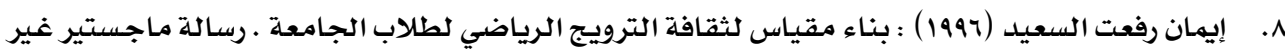
منشورة . كلية التربية الرياضية بنين ، جامعة حلوان . ماكياء

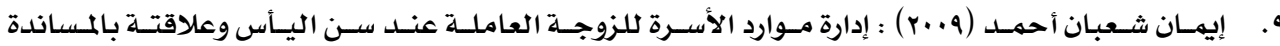

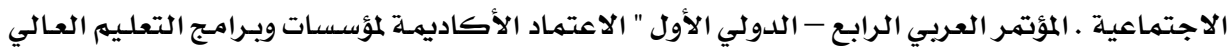

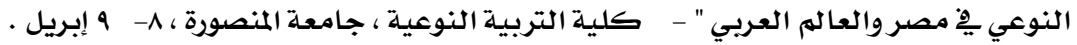

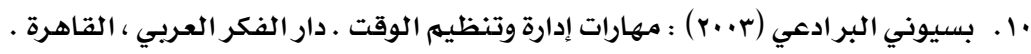

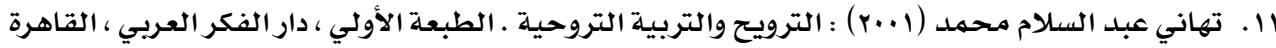

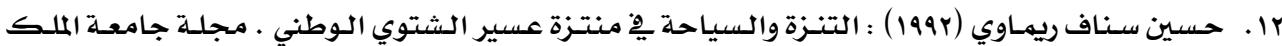

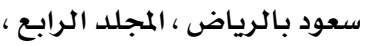

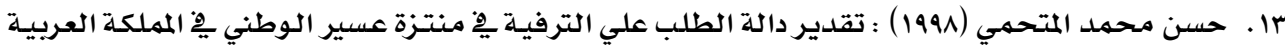

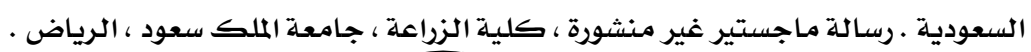


عا. خالد عبد الرحمن السالم ( .... ) : الضبط الاجتماعي والتماسك الأسري ـ الرياض ، طا.

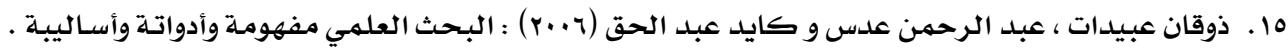

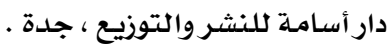

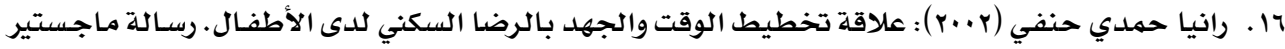

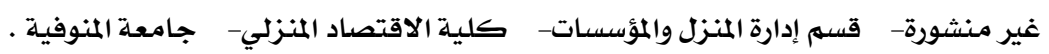

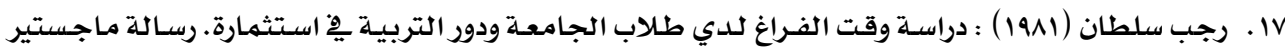

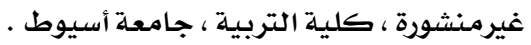

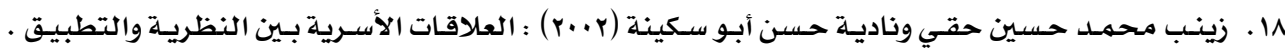

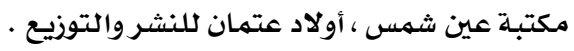

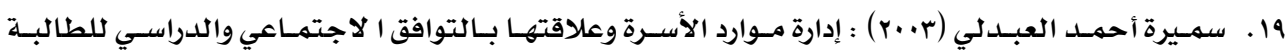

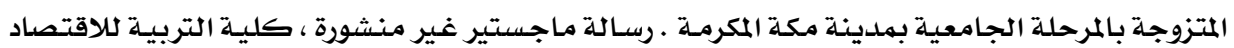
المنزلي ، وكالة كليات البنات . بالمرحلة الجامية بهلينة

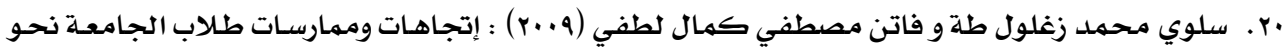

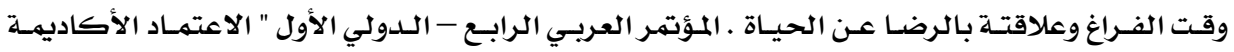

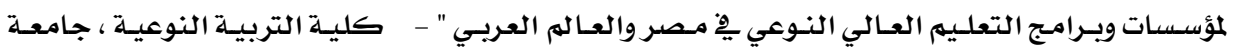

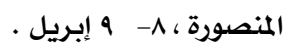

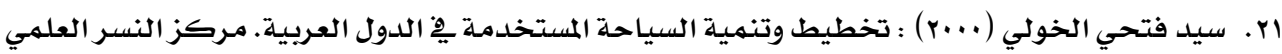

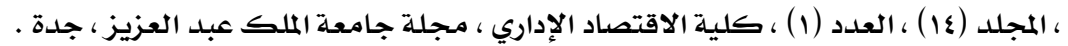

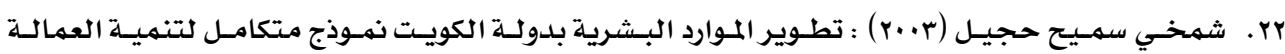

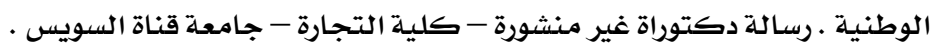

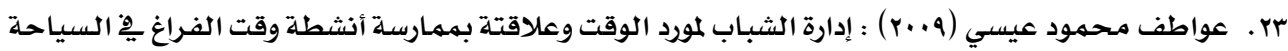

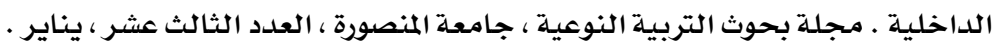

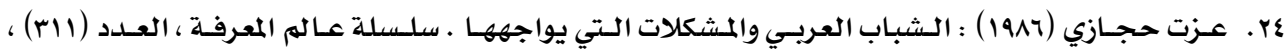
الكويت

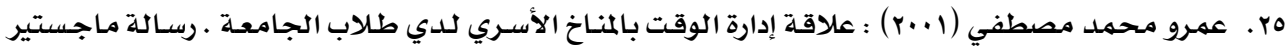

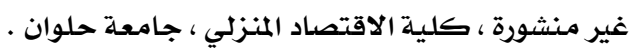

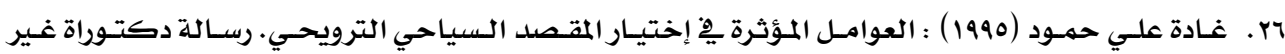

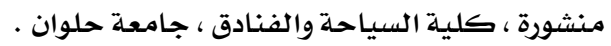

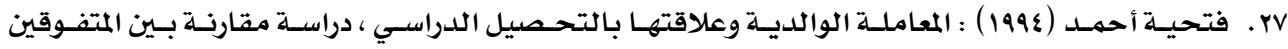

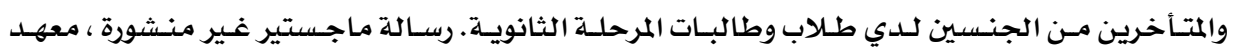

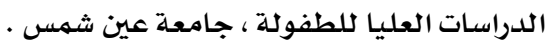

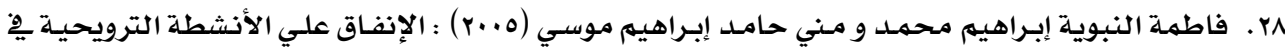

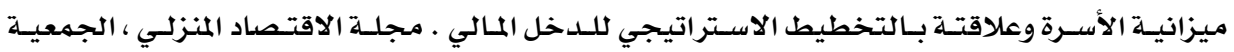

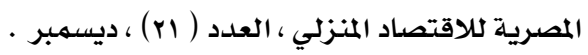




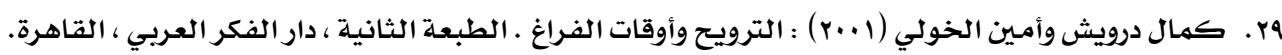

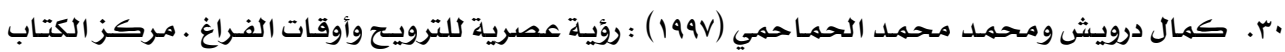
للنشر ، مطبعة التيسير ، القاهرة .

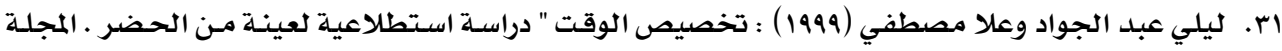

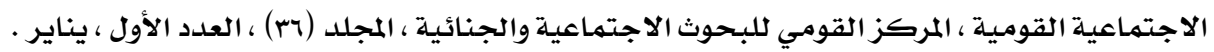

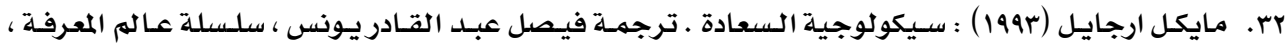

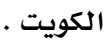

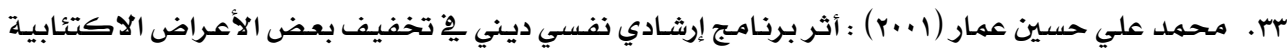

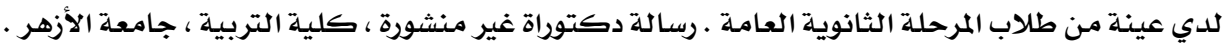

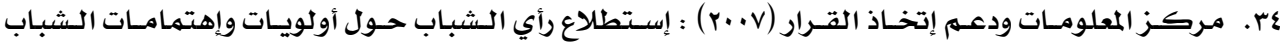

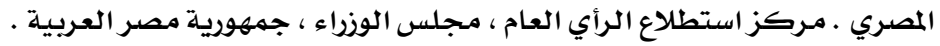

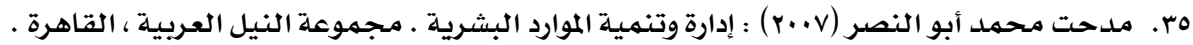

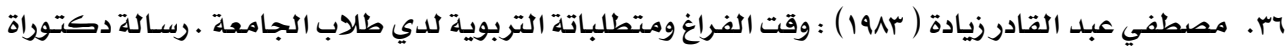

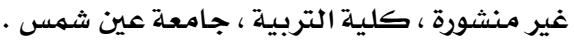

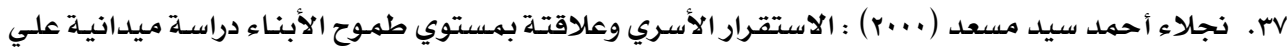

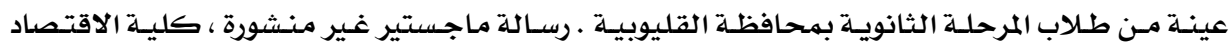

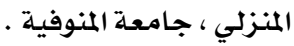

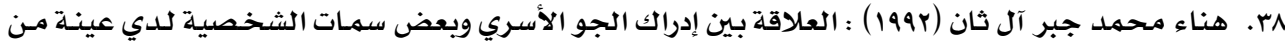

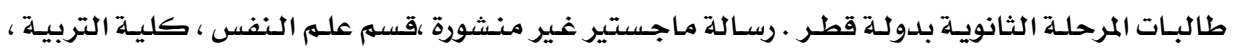

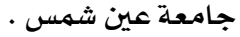

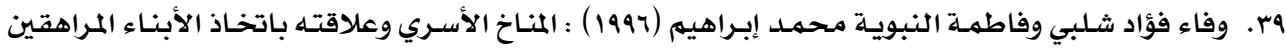

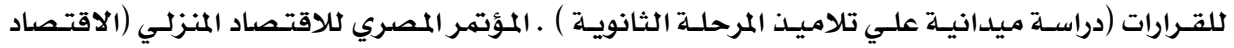

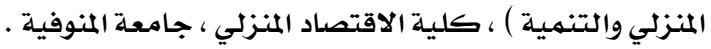

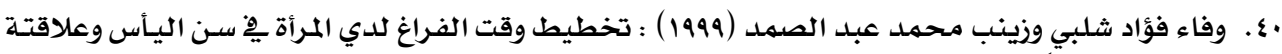

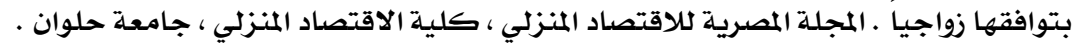

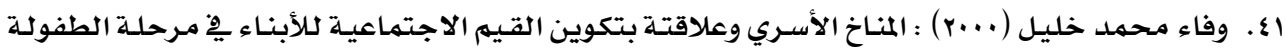

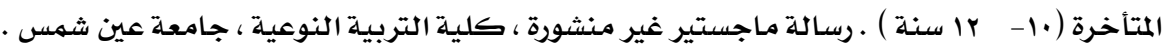

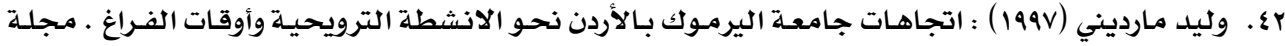

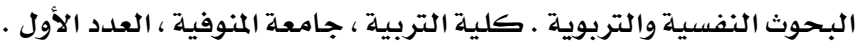

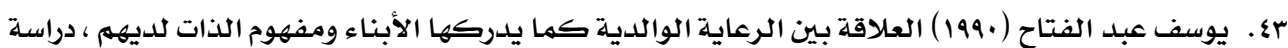

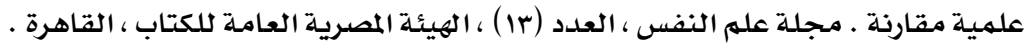




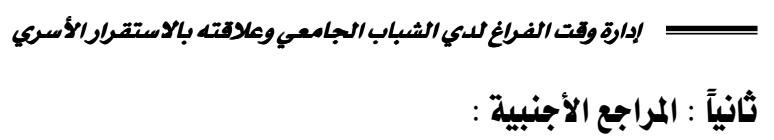

44. Bajan , Peter (1998) : new communities, New Social Norms . StudiaPsychologica . Vol. (40), No. (4), pp. (301-366) .

45. Burt, Chales E., Cohen , L. H. \& Biovck, J. P. (1988) : Perceived family environment as a moderator of young adolescent's life stress adjustment . journal of psychology .

46. Cooper, Judith E. ; Holman, J. ; Braithwaite, F. (1983) : Selfesteem And Family Cohesion : The Child's Repective And Edjustment. Journal of Marriage and the family. Vol. (45), pp. (153-159) .

47. Dammer, beckanne, M. (1995) : The Political Economy Of The Family A Study Of Household Time Use Decision . University of Missouri Columbia .

48. Gecas,V. \& Schawalbe ( 1986) : Parental behavior and adolescent sel-esteem . journal of marriage and the family, Vol. (48) .

49. Hay, Brian (1985) : An Analysis of the multiple recreation activity day trip . ph.D. Texas University .

50. Himes , B. (1980) : The relationship between family environment, Parent-child relationship and adult's self-concept as perceived by adolescents and other family member ( ERIC). Piss , Ab,S., Vol(41).

51. Hoelter,J. \& Harper, L. (1987) : Structural and inter persons Family influences on adolescent self - conception . Journal of marriage and family .

52. Jones Etheli (1996) : Attaining Excellence : the relationship between the variables of family climate as perceived by the child and student achievement, Wagne state university, Hillman - larry - w .

53. Kogan, L. (2008) : The Concept of leisure . Academic Sciences . Moscow , 25.

54. Mary , Fish \& Doug , Waggle (1996) : Current Income Versus Total Expenditure Measures In Regession Models Of Vacation And Pleasure Travel . University of Alabama in Birmingham . Journal of Travel research, Vol. (35), No. (2) .

55. Miriam Lincoln (1981) : Woman, Her Change Of Life . Williams Norgateltd, London printed in Great Britain . p(70) .

56. Richardson, R. A. and Galanlos , N. L. ( 1994) : Young adolescents perception of family environment . Journal of Early Adolescence . Vol. (4) No. (2) . pp. (131-153) . 
57. Turner, Mo, F. ; Kerwski , M. D. ; Mo. F. D. ( 2005) : Physical Inactivity And Socioeconomic Status In Canadian Adolescents. International Journal of Adolescent Medical Health . Jan, Mar, Vol. (17), No, (1), pp. (49-56) .

58. Tran , D. G. (1993) : Family functioning its influences on vietnamese adolescents social functioning and psychological well being. Dissertation Abstracts International, Vol. (54) . No. (3) .

59. Walter R. Cunning Ham, Johan W. Brook Bank (1988) : Gerontology, Harper . Row Publishers, Inc. U.S.A. P.(239) . 